Review

\title{
Palladium-Catalyzed Cross-Coupling Reactions of Perfluoro Organic Compounds
}

\section{Masato Ohashi $^{1, *}$ and Sensuke Ogoshi ${ }^{1,2, *}$}

1 Department of Applied Chemistry, Faculty of Engineering, Osaka University, Suita, Osaka 565-0871, Japan

2 JST, Advanced Catalytic Transformation program for Carbon utilization (ACT-C), Suita, Osaka 565-0871, Japan

* Authors to whom correspondence should be addressed;

E-Mails: ohashi@chem.eng.osaka-u.ac.jp (M.O.); ogoshi@chem.eng.osaka-u.ac.jp (S.O.);

Tel.: +81-6-6879-7393 (M.O. \& S.O.); Fax: +81-6-6879-7394 (M.O. \& S.O.).

Received: 25 June 2014; in revised form: 19 August 2014 / Accepted: 21 August 2014 /

Published: 10 September 2014

\begin{abstract}
In this review, we summarize our recent development of palladium(0)-catalyzed cross-coupling reactions of perfluoro organic compounds with organometallic reagents. The oxidative addition of a $\mathrm{C}-\mathrm{F}$ bond of tetrafluoroethylene (TFE) to palladium( 0 ) was promoted by the addition of lithium iodide, affording a trifluorovinyl palladium(II) iodide. Based on this finding, the first palladium-catalyzed cross-coupling reaction of TFE with diarylzinc was developed in the presence of lithium iodide, affording $\alpha, \beta, \beta$-trifluorostyrene derivatives in excellent yield. This coupling reaction was expanded to the novel $\mathrm{Pd}(0) / \mathrm{PR}_{3}$-catalyzed cross-coupling reaction of TFE with arylboronates. In this reaction, the trifluorovinyl palladium(II) fluoride was a key reaction intermediate that required neither an extraneous base to enhance the reactivity of organoboronates nor a Lewis acid additive to promote the oxidative addition of a $\mathrm{C}-\mathrm{F}$ bond. In addition, our strategy utilizing the synergetic effect of $\mathrm{Pd}(0)$ and lithium iodide could be applied to the $\mathrm{C}-\mathrm{F}$ bond cleavage of unreactive hexafluorobenzene $\left(\mathrm{C}_{6} \mathrm{~F}_{6}\right)$, leading to the first $\mathrm{Pd}(0)$-catalyzed cross-coupling reaction of $\mathrm{C}_{6} \mathrm{~F}_{6}$ with diarylzinc compounds.
\end{abstract}

Keywords: C-F bond activation; palladium; perfluoroalkene; perfluoroarene; cross-coupling; diarylzinc; arylboronate 


\section{Introduction}

Efficient methods have been developed for the synthesis of organofluorine compounds, because functionalized fluorinated organic compounds are crucial in our daily life [1-9]. In particular, the transformation of perfluoro organic compounds is an efficient and economical method for the preparation of highly functionalized organofluorine compounds. Trifluorovinyl compounds, such as $\alpha, \beta, \beta$-trifluorostyrene and their derivatives, have attracted increased attention, since they are regarded as a potential monomer for the preparation of polymers with a perfluorinated main chain [10-12]. Nevertheless, conventional methods for their preparation have thus far not been fully established. For instance, most of the initial preparation routes for trifluorostyrenes required multistep reactions [13-16]. A few reactions substituting the fluorine atom on fluoroolefines, including tetrafluoroethylene (1; TFE), with a carbon nucleophile are considered classic procedures [17-23]. These reactions involve an addition-elimination mechanism, and they often suffer from undesired side-reactions, such as a multi-substitution reaction, even at low reaction temperatures [17,19]. $\operatorname{Pd}(0)$-catalyzed cross-coupling reactions of trifluorovinylzinc, tin, or borate reagents emerged in the 1980s as more direct synthetic methods [24-33]. A synthetic route involving a more stable trifluorovinyl borate has recently been developed to replace the zinc or tin reagents [34,35]. Alternative routes to synthesize ( $\alpha, \beta, \beta$-trifluoro)styrenes via the cross-coupling of chlorotrifluoroethylene with arylboronic acids have recently been reported [36,37]. Against such a background, we started developing a novel strategy for their preparation from $\mathbf{1}$, because $\mathbf{1}$ is an economical bulk organofluorine feedstock for the production of poly(tetrafluoroethylene) and co-polymers with other alkenes [38-40]. However, to the best of our knowledge, no catalytic reactions involving $\mathbf{1}$ had been reported until we reported the first catalytic transformation reaction [41], while homogeneous catalytic reactions involving $\mathrm{C}-\mathrm{F}$ bond activation have received an increasing amount of attention [42-53]. The $\mathrm{C}-\mathrm{F}$ bond activation reaction of 1 had been achieved only in a few stoichiometric reactions [54-56]. In a groundbreaking study of C-F bond activation in 1, Kemmit reported that LiI promoted the oxidative addition of 1 to platinum(0) [54]. This observation inspired us to develop a palladium-catalyzed cross-coupling reaction using 1 with organometallic compounds.

This review is the first report of the formation, structure and reactivity of a trifluorovinyl palladium(II) complex from the oxidative addition of the $\mathrm{C}-\mathrm{F}$ bond of $\mathbf{1}$ to palladium(0) in the presence of LiI. The first palladium-catalyzed cross-coupling reaction of $\mathbf{1}$ with aryl zinc compounds in the presence of LiI is also discussed [41,57]. We then discuss the development of the active $\mathrm{Pd}(0) / \mathrm{PR}_{3}$ species that enabled the oxidative addition of the $\mathrm{C}-\mathrm{F}$ bond of 1 using no additives. By employing the $\mathrm{Pd}(0) / \mathrm{PR}_{3}$ species as a catalytic precursor, a Suzuki-Miyaura type of a cross-coupling reaction of 1 with arylboronates was successfully achieved [58]. This cross-coupling reaction required neither an extraneous base to enhance the reactivity of organoboron reagents nor a Lewis acid to promote the oxidative addition of a $\mathrm{C}-\mathrm{F}$ bond.

The transformation of perfluoroarenes into highly functionalized perfluoroaryl-substituted compounds is also an efficient and economical strategy. Radius et al. reported a coupling reaction of octafluorotoluene $\left(\mathrm{C}_{7} \mathrm{~F}_{8}\right)$ and decafluorobiphenyl $\left(\mathrm{C}_{12} \mathrm{~F}_{10}\right)$ with arylboronic acid in the presence of a catalytic amount of $\mathrm{NHC}$-nickel( 0 ) catalyst (where $\mathrm{NHC}$ represents $\mathrm{N}$-Heterocyclic carbene) [59]. This group also demonstrated the usefulness of a NHC-nickel $(0)$ complex for the $\mathrm{C}-\mathrm{F}$ bond activation of 
hexafluorobenzene $\left(\mathrm{C}_{6} \mathrm{~F}_{6}\right)$, and the $\mathrm{Ni}(0) / \mathrm{NHC}$ complex did indeed show catalytic activity toward the hydrodefluorination of $\mathrm{C}_{6} \mathrm{~F}_{6}$ [60-62]. However, an efficient catalytic transformation of $\mathrm{C}_{6} \mathrm{~F}_{6}$ involving a $\mathrm{C}-\mathrm{C}$ bond formation is very rare. To the best of our knowledge, only two examples of transition metal-catalyzed $\mathrm{C}-\mathrm{C}$ bond formation reactions using $\mathrm{C}_{6} \mathrm{~F}_{6}$ to give biaryls have been reported $[63,64]$. Yoshikai and Nakamura reported the coupling reaction of multi-fluorinated benzenes with aryl zinc catalyzed by a nickel catalyst ligated with alkoxydiphosphine, and that group also achieved the selective activation of a $\mathrm{C}-\mathrm{F}$ bond [64]. From a practical point of view, nonetheless, there remains no easily accessible catalyst system that is applicable for a coupling reaction that could introduce a perfluorinated aryl group to a certain position of arene compounds. We know the synergistic effect of $\operatorname{Pd}(0)$ and lithium iodide has been successfully applied to the $\mathrm{C}-\mathrm{F}$ bond cleavage of $\mathrm{C}_{6} \mathrm{~F}_{6}$, and the first development of the $\mathrm{Pd}(0)$-catalyzed cross-coupling reaction of $\mathrm{C}_{6} \mathrm{~F}_{6}$ with diarylzinc has been achieved [65]. This revies introduces a possible reaction path based on certain stoichiometric reactions and on the robustness of trans- $\left(\mathrm{PCy}_{3}\right)_{2} \mathrm{Pd}(\mathrm{I})\left(\mathrm{C}_{6} \mathrm{~F}_{5}\right)$ formed by the oxidative addition of $\mathrm{C}_{6} \mathrm{~F}_{6}$ to $\mathrm{Pd}\left(\mathrm{PCy}_{3}\right)_{2}$ in the presence of LiI.

\section{Results and Discussion}

\subsection{Pd(0)-Catalyzed Cross-Coupling Reactions of Tetrafluoroethylene with Diarylzinc Reagents}

The treatment of LiI with $\left(\eta^{2}-\mathrm{CF}_{2}=\mathrm{CF}_{2}\right) \mathrm{Pd}\left(\mathrm{PPh}_{3}\right)_{2}$ (2a) in THF at room temperature promoted the oxidative addition of a $\mathrm{C}-\mathrm{F}$ bond of THF to give a trifluorovinyl palladium(II) iodide (3; Scheme 1). In contrast to the known platinum analog, $\left(\eta^{2}-\mathrm{CF}_{2}=\mathrm{CF}_{2}\right) \mathrm{Pt}\left(\mathrm{PPh}_{3}\right)_{2}$ [54], the $\mathrm{C}-\mathrm{F}$ bond cleavage on palladium took place with no heating of the reaction mixture. An attempt to cleave the carbon-fluorine bond in $\mathbf{2 a}$ at $100{ }^{\circ} \mathrm{C}$ in the absence of LiI resulted in the decomposition of $\mathbf{2 a}$ along with the liberation of a TFE molecule and the precipitation of Pd black. Thus, cleavage of the $\mathrm{C}-\mathrm{F}$ bond, generating $\mathbf{3}$, required LiI to as a Lewis acid to enhance the elimination ability of fluorine. The formation of a strong $\mathrm{Li}-\mathrm{F}$ bond might also be important for oxidative addition at room temperature. The ORTEP drawing of $\mathbf{3}$ definitely shows that the palladium in $\mathbf{3}$ adopted a square-planar coordination geometry and was coordinated with two $\mathrm{PPh}_{3}$ ligands in a trans manner (Figure 1). Complex 3 is the first example of a mononuclear trifluorovinyl complex generated by the carbon-fluorine bond cleavage of 1 with a well-defined structure [53,66].

Scheme 1. C-F bond cleavage of 1 on palladium.
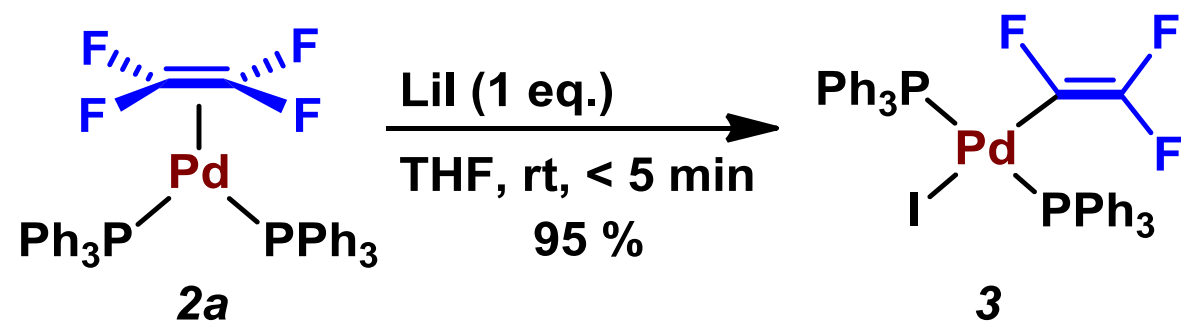
Figure 1. Molecular structure of $\mathbf{3}$ with thermal ellipsoids at the $30 \%$ probability level. $\mathrm{H}$ atoms are omitted for clarity.

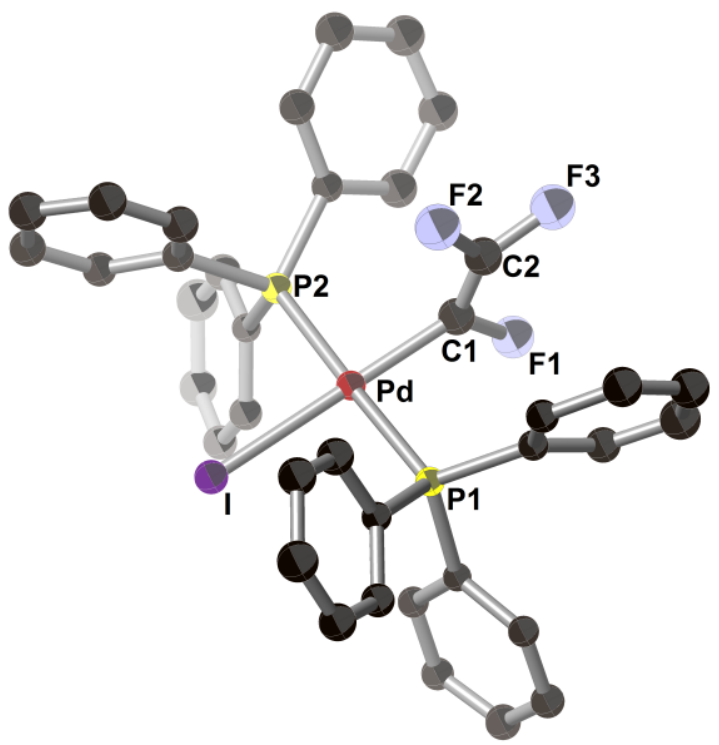

Complex 3 seemed to be a promising reaction intermediate for the preparation of various trifluorovinyl compounds via cross-coupling reactions of TFE with organometallic reagents. In particular, each reaction step in the cross-coupling of TFE with arylmetal reagents to give trifluorovinylarenes had to occur at a relatively low temperature, since the undesired side-reactions of the resultant trifluorovinylarenes gave a complex mixture. In fact, the [2+2] cyclodimerization of $\left(\alpha, \beta, \beta\right.$-trifluoro)styrene occurred in a head-to head manner at $80{ }^{\circ} \mathrm{C}$ to give a mixture of cis and trans isomers [27,67]. Therefore, $\mathbf{3}$ was reacted with a stoichiometric amount of $\mathrm{ZnPh}_{2}$ (4a) to determine if the expected reaction would occur at room temperature to give $(\alpha, \beta, \beta$-trifluoro)styrene (5a). Although the reaction of $\mathbf{3}$ with 0.5 equiv of $\mathbf{4 a}$ in THF resulted in the formation of a complicated mixture that contained a small amount of the expected compound 5a, in the presence of LiI and DBA (trans,trans-dibenzylideneacetone), the reaction of $\mathbf{3}$ with $\mathbf{4 a}$ proceeded smoothly to give $\mathbf{5 a}$ in $87 \%$ yield (Scheme 2). Both LiI and DBA are potential additives in the cross-coupling reaction, since the reaction of TFE with $\mathrm{Pd}_{2}(\mathrm{dba})_{3}$ and $\mathrm{PPh}_{3}$ in the presence of LiI, giving $\mathbf{3}$, simultaneously yielded an uncoordinated DBA. The role of lithium iodide in this reaction was the formation of reactive zincates such as $\mathrm{Li}[\mathrm{ArZnXI}]$ ( $X=$ Ar or I, vide infra) [68]. By contrast, platinum is an unlikely catalyst for the cross-coupling reaction, because the oxidative addition of TFE to platinum( 0 ) requires both a much higher temperature and a longer reaction time (at $95^{\circ} \mathrm{C}$ for $24 \mathrm{~h}$ ) [54].

A logical extension of this reaction scheme was to conduct a Pd-catalyzed coupling reaction of TFE with diarylzinc in the presence of LiI, and the results are summarized in Table 1. In the presence of $2.5 \mathrm{~mol}_{\%}$ of $\mathrm{Pd}_{2}(\mathrm{dba})_{3}$ and $10 \mathrm{~mol} \%$ of $\mathrm{PPh}_{3}$, the coupling reaction of 1 with $4 \mathbf{a}$, which was prepared by treating $\mathrm{ZnCl}_{2}$ with 2 equiv of $\mathrm{PhMgBr}$ in situ, took place at room temperature. The desired product 5a was obtained in $48 \%$ yield (entry 1). Under the same reaction conditions, the reaction with isolated $\mathrm{ZnPh}_{2}$ occurred somewhat slowly compared with $\mathrm{ZnPh}_{2}$ prepared in situ (entry 2). As expected from the stoichiometric reactions, the addition of lithium iodide was essential for the Pd-catalyzed coupling reaction (entry 3). Although either elongation of the reaction time or elevation of the reaction temperature was required, even with reduced catalyst loading $\left(0.01 \mathrm{~mol} \%\right.$ of $\left.\operatorname{Pd}_{2}(\mathrm{dba})_{3}\right)$, the catalytic 
reaction proceeded smoothly at $40{ }^{\circ} \mathrm{C}$ to give 5a in $72 \%$ yield (entry 4 ). The rate of the coupling reaction was remarkably enhanced by the omission of $\mathrm{PPh}_{3}$ from the catalytic system, and $\mathbf{5 a}$ was obtained in $73 \%$ yield (entry 5). By contrast, in the absence of $\operatorname{Pd}(0)$, the reactions of 1 with $4 \mathbf{a}$ were negligible, indicating that $\operatorname{Pd}(0)$ catalyzed the coupling reaction with or without lithium iodide (entries 6 and 7).

Scheme 2. Reactions of $\mathbf{3}$ with $\mathrm{ZnPh}_{2}$ (4a) in the presence of additives.

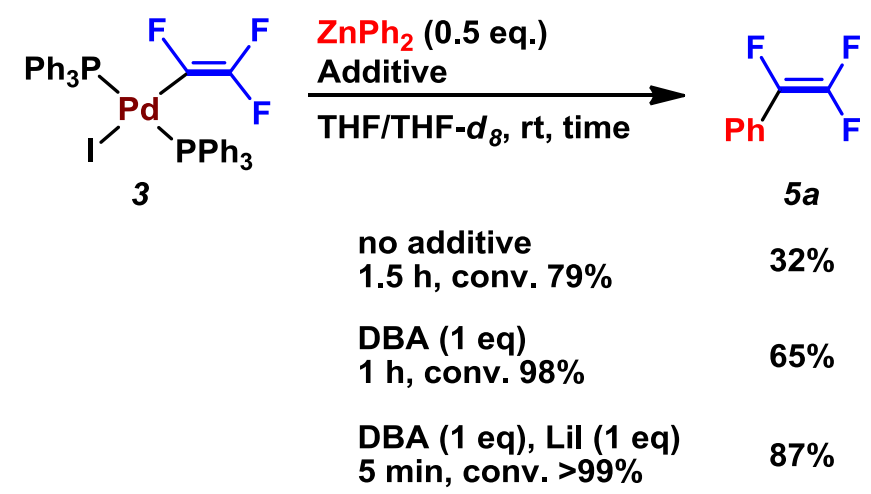

Table 1. Optimization of the reaction conditions for the $\mathrm{Pd}(0)$-catalyzed cross-coupling reaction of 1 with $4 \mathbf{a}$. General conditions: solvent; $0.5 \mathrm{~mL}$. All reactions were conducted in a pressure-tight NMR tube. Yields, based on aryl group, were determined by ${ }^{19} \mathrm{~F}$ NMR analysis of the crude product using $\alpha, \alpha, \alpha$-trifluorotoluene as an internal standard.

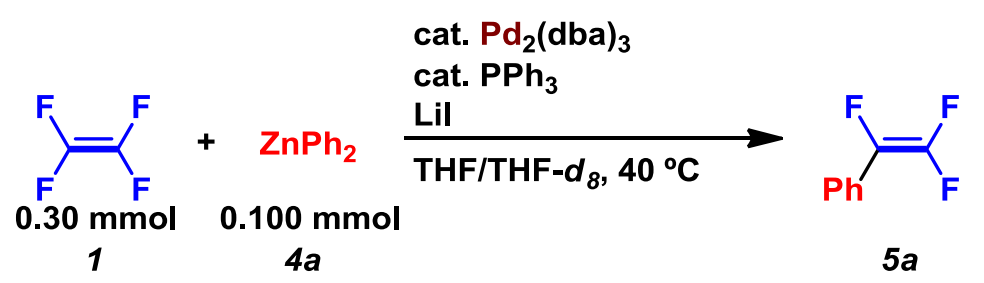

\begin{tabular}{|c|c|c|c|c|c|c|}
\hline Entry & $\mathrm{Pd}_{2}(\mathrm{dba})_{3} / \mathrm{mol}^{2} \%$ & $\mathrm{PPh}_{3} / \mathrm{mol} \%$ & Preparation of $\mathrm{ZnPh}_{2}$ (4a) & LiI/mmol & Time/h & Yield/\% \\
\hline 1 & 2.5 & 10.0 & $\mathrm{ZnCl}_{2}+2 \mathrm{PhMgBr}$ & - & 24 & 48 \\
\hline 2 & 2.5 & 10.0 & isolated $\mathrm{ZnPh}_{2}$ & - & 24 & 19 \\
\hline 3 & 2.5 & 10.0 & $\mathrm{ZnCl}_{2}+2 \mathrm{PhMgBr}$ & 0.240 & 9 & 61 \\
\hline 4 & 0.01 & 0.04 & $\mathrm{ZnCl}_{2}+2 \mathrm{PhMgBr}$ & 0.240 & 24 & 72 \\
\hline 5 & 0.01 & - & $\mathrm{ZnCl}_{2}+2 \mathrm{PhMgBr}$ & 0.240 & 4 & 73 \\
\hline 6 & - & - & $\mathrm{ZnCl}_{2}+2 \mathrm{PhMgBr}$ & 0.240 & 24 & 3 \\
\hline 7 & - & - & $\mathrm{ZnCl}_{2}+2 \mathrm{PhMgBr}$ & - & 24 & 9 \\
\hline
\end{tabular}

The scope of diarylzinc reagents was investigated using the optimized reaction conditions (Scheme 3). The treatment of $\mathbf{1}$ with $\mathbf{4 a}$, which was prepared by the reaction of $\mathrm{ZnCl}_{2}$ with $\mathrm{PhMgCl}$, gave 5a in $81 \%$ yield, which marked the highest reactivity from among the arylzinc reagents $\left(\mathrm{TON}=8100\right.$, entry 9). In addition, the reactions with $\mathrm{Zn}\left(4-\mathrm{Me}-\mathrm{C}_{6} \mathrm{H}_{4}\right)_{2}(\mathbf{4 b})$ and $\mathrm{Zn}\left(3-\mathrm{Me}-\mathrm{C}_{6} \mathrm{H}_{4}\right)_{2}(\mathbf{4 c})$ gave the monoaryl-substituted products $\mathbf{5 b}$ and $\mathbf{5 c}$ in $75 \%$ and $72 \%$ yields, respectively, while the reaction with $\mathrm{Zn}\left(2-\mathrm{Me}-\mathrm{C}_{6} \mathrm{H}_{4}\right)_{2}$ (4d) gave only $57 \%$ yield of $\mathbf{5 d}$. The reactions with fluoro-substituted aryl zinc reagents (4e and $\mathbf{4 f}$ ) yielded the corresponding products (5e and $\mathbf{5 f}$ ) in $53 \%$ and $55 \%$ yields, respectively. The reactions with $p$-substituted arylzinc reagents, such as $\mathrm{Zn}\left(4-\mathrm{MeO}-\mathrm{C}_{6} \mathrm{H}_{4}\right)_{2}(\mathbf{4 g})$ and 
$\mathrm{Zn}(4-\text { styryl })_{2}(\mathbf{4 h})$, also afforded the corresponding products (5g and $\left.\mathbf{5 h}\right)$ in good yields. By contrast, $\mathrm{Zn}\left(4-\mathrm{CF}_{3}-\mathrm{C}_{6} \mathrm{H}_{4}\right)_{2}(\mathbf{4 i}), \mathrm{Zn}\left(4-\mathrm{Cl}-\mathrm{C}_{6} \mathrm{H}_{4}\right)_{2}(\mathbf{4 j})$ and $\mathrm{Zn}\left(4-\mathrm{MeS}-\mathrm{C}_{6} \mathrm{H}_{4}\right)_{2}$ (4k) required prolonged reaction times to yield the corresponding products $(\mathbf{5 i}-\mathbf{k})$ in moderate yields. In addition, the reaction with $\mathrm{Zn}\left(4-\mathrm{Me}_{2} \mathrm{~N}-\mathrm{C}_{6} \mathrm{H}_{4}\right)_{2}$ (4I) was terminated within 2 hours, and as a consequence, the yield of the desired product (5l) remained at 30\%. Use of $\mathrm{Zn}(2 \text {-thienyl) })_{2}(\mathbf{4 m})$ allowed the reaction with $\mathbf{1}$ to proceed to give $5 \mathbf{m}$, although much longer reaction time was required and the product yield was low. This catalytic system was also successfully applied to $\mathrm{Zn}(2 \text {-naphthyl })_{2}(\mathbf{4 n})$, which gave the corresponding product (5n) in $61 \%$ yield. The reaction products were isolated as a THF solution due to the occurrence of the cyclodimerization to give hexafluoro-cyclobutane derivatives at a higher concentration [69]. Relatively lower isolated yields were caused either by high volatility even at room temperature or by cyclodimerization.

Scheme 3. $\mathrm{Pd}(0)$-Catalyzed Coupling Reaction of TFE (1) with $\mathrm{ZnAr}_{2}$ (4). General conditions: 1 (3.5 atm, >0.30 mmol, estimated from an equation of state), 4 (0.100 mmol, in situ prepared by treating of $\mathrm{ZnCl}_{2}$ with 2 equiv of $\mathrm{ArMgBr}$ ), solvent; $0.5 \mathrm{~mL}$. All reactions were conducted in a pressure-tight NMR tube. Yields, based on aryl group, were determined by ${ }^{19} \mathrm{~F}$ NMR analysis of the crude product using $\alpha, \alpha, \alpha$-trifluorotoluene as an internal standard. The values in parentheses are of isolated yield.
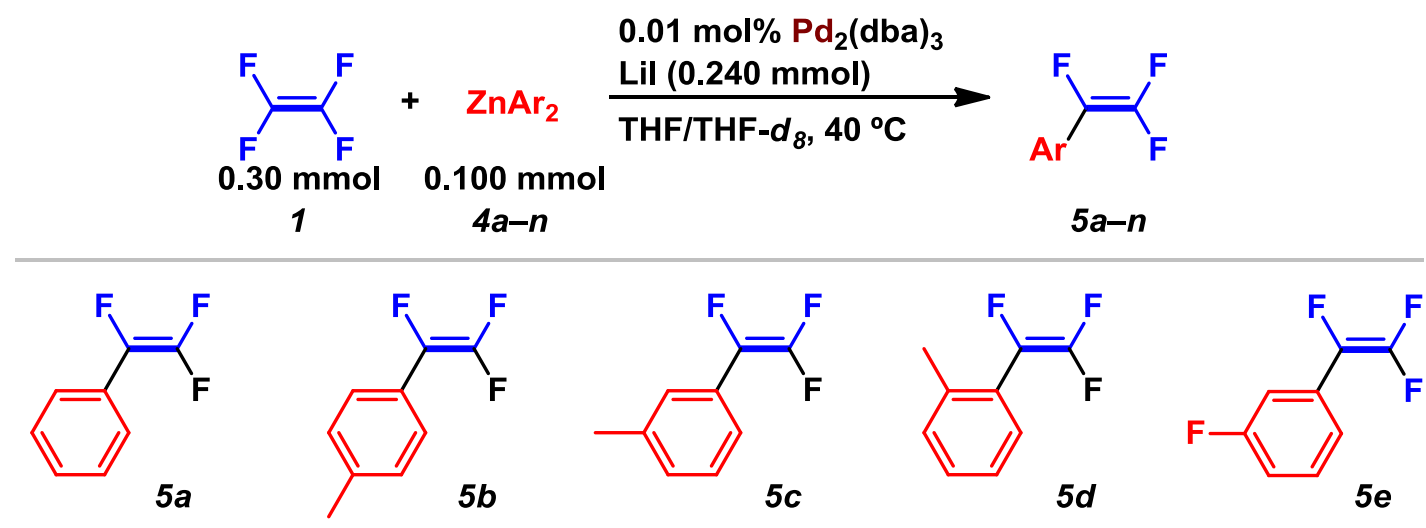

$81 \%(2 \mathrm{~h})$

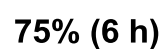

$72 \%(4 \mathrm{~h})$

[62\% $\left.\left(40{ }^{\circ} \mathrm{C}, 8 \mathrm{~h}\right)\right]$

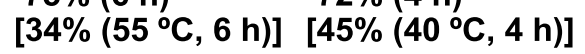

$57 \%(8 \mathrm{~h})$

$53 \%(8 \mathrm{~h})$
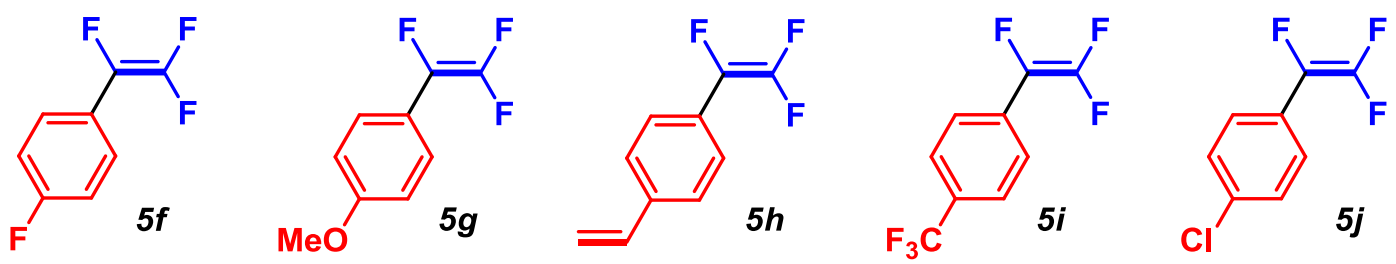

$55 \%(4 \mathrm{~h})$

$63 \%(2.5 \mathrm{~h})$

$65 \%$ (4 h)

$31 \%$ (18 h)

$37 \%(28 \mathrm{~h})$

[51\% $\left.\left(55^{\circ} \mathrm{C}, 8 \mathrm{~h}\right)\right]\left[39 \%\left(55^{\circ} \mathrm{C}, 5 \mathrm{~h}\right)\right]\left[71 \%\left(55^{\circ} \mathrm{C}, 8 \mathrm{~h}\right)\right]\left[14 \%\left(55^{\circ} \mathrm{C}, 18 \mathrm{~h}\right)\right]\left[10 \%\left(55^{\circ} \mathrm{C}, 28 \mathrm{~h}\right)\right]$

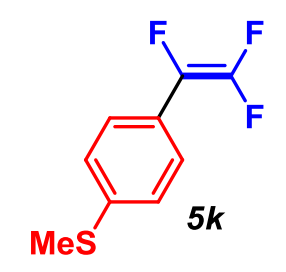

$41 \%(21 \mathrm{~h})$

[37\% (55 $\left.\left.{ }^{\circ} \mathrm{C}, 21 \mathrm{~h}\right)\right]$

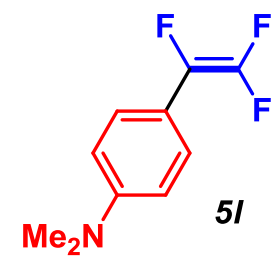

$30 \%(2 \mathrm{~h})$

[25\% (rt, 2 h)]

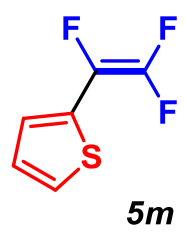

$34 \%(75 \mathrm{~h})$

$\left[14 \%\left(60^{\circ} \mathrm{C}, 14 \mathrm{~h}\right)\right]$

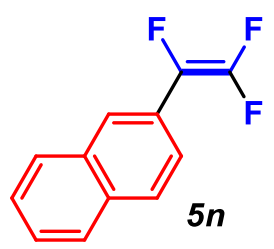

$61 \%(4 \mathrm{~h})$

$\left[37 \%\left(60^{\circ} \mathrm{C}, 4 \mathrm{~h}\right)\right]$ 
Based on the results described above, the Pd-catalyzed monoaryl substitution reaction of $\mathbf{1}$ might proceed via the mechanism depicted in Scheme 4. Coordination of a TFE molecule to $\operatorname{Pd}(0)$ would take place to generate an $\eta^{2}$-TFE species $(\mathbf{B})$. Then oxidative addition of a $\mathrm{C}-\mathrm{F}$ bond to $\operatorname{Pd}(0)$ is promoted by lithium iodide, generating a trifluorovinyl palladium(II) intermediate (C). Transmetalation of $\mathbf{C}$ with $\mathrm{Li}[\mathrm{ArZnXI}]$ would yield a transient aryl palladium intermediate (D), which would undergo reductive elimination to afford ( $\alpha, \beta, \beta$-trifluoro)styrene derivative 5 along with regeneration of the $\mathrm{Pd}(0)$ species. The addition of lithium iodide is essential not only for accelerating cleavage of the carbon-fluorine bond, but also for enhancing the reactivity of arylzinc reagents via the formation of zincates, such as Li[ArZnXI].

Scheme 4. A plausible reaction mechanism.

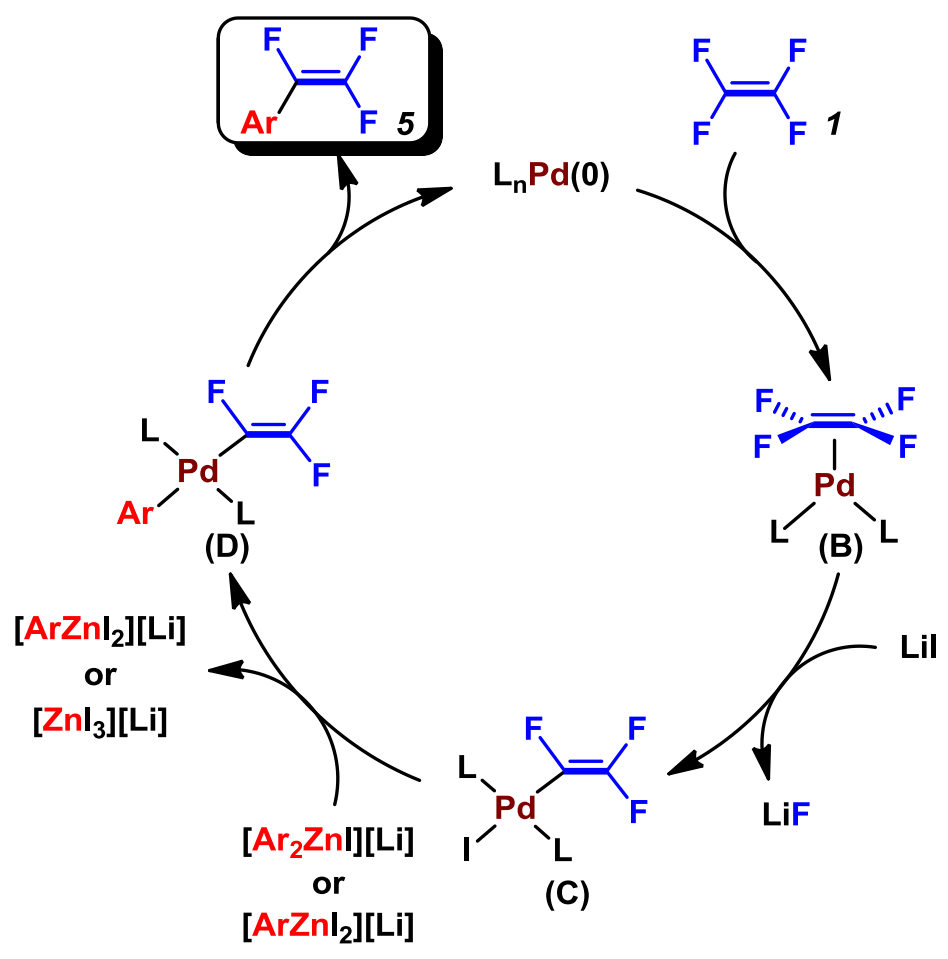

\subsection{Pd(0)-Catalyzed Cross-Coupling Reactions of Tetrafluoroethylene with Arylboronates}

Our next concern was to apply the $\mathrm{C}\left(\mathrm{sp}^{2}\right)-\mathrm{F}$ bond activation methodology to a Suzuki-Miyaura type $\mathrm{C}-\mathrm{C}$ bond formation reaction that generally offers the advantages of tolerance across a broad range of functional groups [70-74]. Most of the reported Suzuki-Miyaura type cross-coupling reactions via C-F bond cleavage, employing either highly electron-deficient organofluorine compounds or those bearing a directing group, have traditionally been conducted in the presence of a base [59,75-85], whereas fluoride anion itself is regarded as a good activator for neutral organoboron reagents. The role of a base in a Suzuki-Miyaura coupling reaction is generally considered to follow one of two patterns; either converting a neutral organoboron compound into a nucleophilic boronate, or converting a palladium halide intermediate into an active palladium species via a ligand exchange reaction by the base $[86,87]$. In fact, Widdowson pointed out the possibility that the use of an extraneous base should be, in principle, catalytic [75]. Such a reaction, however, has not been developed. Some coupling reactions with organoboran reagents are known to proceed under neutral conditions, in which such an 
active species as palladium alkoxy or acyl complex is generated in situ via the oxidative addition of a $\mathrm{C}-\mathrm{O}$ bond $[75,88,89]$. We speculated that if the transition-metal fluorides generated via $\mathrm{C}-\mathrm{F}$ bond cleavage would have reactivity sufficiently high so as to act as a fluoride donor, the development of base-free $\mathrm{C}-\mathrm{C}$ couplings with organoboron reagents would bring a significant concept to the Suzuki-Miyaura coupling reaction with organofluorine compounds. Thus, we started developing a base-free $\mathrm{C}-\mathrm{C}$ bond formation reaction of 1 with arylboronates in the presence of a $\mathrm{Pd}(0)$ catalyst.

We began by seeking an active species that could cleave the $\mathrm{C}-\mathrm{F}$ bond of $\mathbf{1}$ without additives, because our original protocol using LiI eliminated the chance to generate a transition-metal fluoride intermediate in return for efficient $\mathrm{C}-\mathrm{F}$ bond cleavage [41,54-56,90]. As a result, the thermolysis of $\left(\eta^{2}-\mathrm{CF}_{2}=\mathrm{CF}_{2}\right) \mathrm{Pd}\left(\mathrm{PCy}_{3}\right)_{2}(\mathbf{2 b})$ in THF at $100{ }^{\circ} \mathrm{C}$ under a $\mathrm{N}_{2}$ atmosphere underwent a $\mathrm{C}-\mathrm{F}$ bond activation of 1 to give an expected trifluorovinylpalladium(II) fluoride (6) in 45\% yield (Scheme 5). NMR observation revealed the concomitant formation of a palladium 2-perfluorobutenyl species (7) as well as $\mathrm{Pd}\left(\mathrm{PCy}_{3}\right)_{2}$. Complex 7 was identified on the basis of the similarity of the ${ }^{19} \mathrm{~F}$ NMR patterns observed in perfluoro2-butenyl zinc species, $\mathrm{CF}_{3}(\mathrm{ZnX}) \mathrm{C}=\mathrm{CFCF}_{3}$ [91]. The recovery of $\mathrm{Pd}\left(\mathrm{PCy}_{3}\right)_{2}$ $(26 \%)$ indicated the existence of a coordination-dissociation equilibrium of $\mathbf{1}$ to palladium under the reaction conditions. Therefore, this reaction was carried out under a TFE atmosphere (1 atm), leading to an improvement in the yield of 6. By contrast, as already mentioned above, the corresponding palladium fluoride analog could not be generated at all by heating the $\mathrm{PPh}_{3}$ analog 2a [41]. In the ${ }^{19} \mathrm{~F}$ NMR spectrum of $\mathbf{6}$, characteristic upfield-shifted resonance attributable to a fluorine adjacent to palladium appeared at $-317.9 \mathrm{ppm}$. To the best of our knowledge, the examples of fluoropalladium complexes generated via the oxidative addition of a C-F bond are very rare [82,92-94]. In addition, complex 6 marked the first example of a structurally well-defined oxidative addition product of $\mathbf{1}$ on a transition metal without the use of Lewis acid additives.

Scheme 5. Generation of trifluorovinylpalladium(II) fluoride via C-F bond cleavage of $\mathbf{1}$.

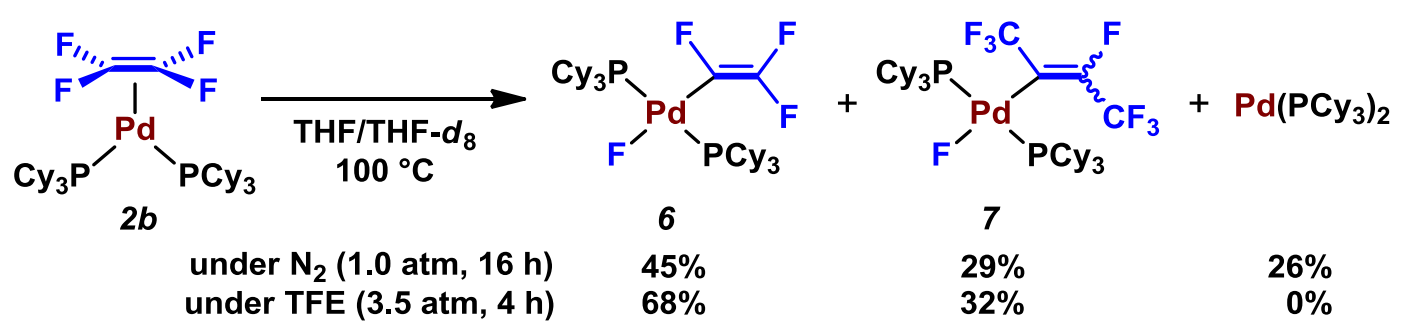

We next examined the reaction of 6 with a stoichiometric amount of 5,5-dimethyl-2-phenyl-1,3,2dioxaborinane (8a) to evaluate the degree of its reactivity toward organoborane reagents. The treatment of $\mathbf{6}$ with 4 equiv of $\mathbf{8 a}$ in the presence of DBA at $100{ }^{\circ} \mathrm{C}$ for $2 \mathrm{~h}$ afforded $\mathbf{5 a}$ in $75 \%$ yield (Scheme 6). In contrast, no $\mathrm{C}-\mathrm{C}$ bond formation occurred, even for a prolonged reaction time, when $8 \mathbf{a}$ was treated with the corresponding palladium iodide (9a) that reacts with $\mathbf{4 a}$. In addition, neither the corresponding palladium bromide (9b) nor chloride (9c) underwent a coupling reaction with $8 \mathbf{a}$. These observations clearly show that the $\mathrm{C}-\mathrm{C}$ bond formation with organoboron reagents is unique to palladium fluoride 6 among corresponding palladium halides. In fact, the $\operatorname{Pd}(0)$-catalyzed coupling reaction of chlorotrifluoroethylene with $\mathbf{8 a}$ in the absence of a base gave no coupling products, probably due to the generation of the unreactive trifluorovinylpalladium chloride intermediate. As 
mentioned above, the Pd-catalyzed coupling reaction of chlorotrifluoroethylene with arylboronic acids in the presence of a base has been reported [36,37].

Scheme 6. Reactivity of palladium trifluorovinyl halides towards $\mathbf{8 a}$.

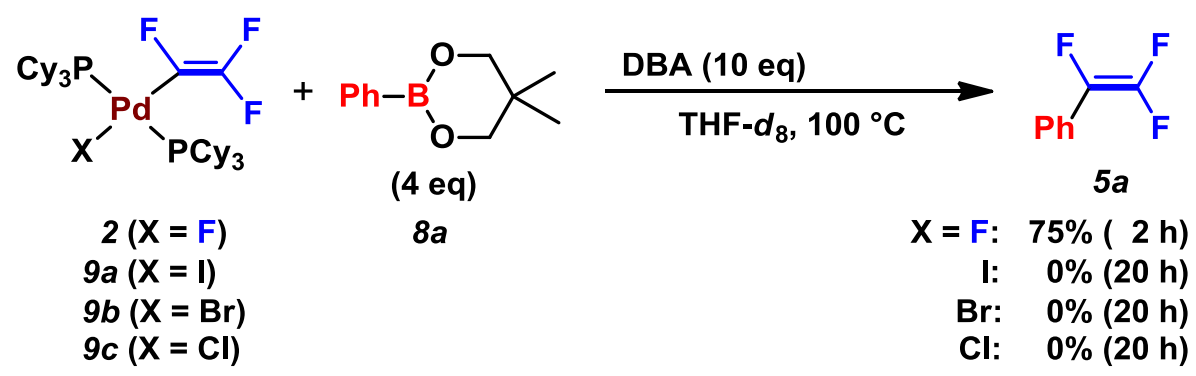

It seemed logical to apply this reaction scheme to a palladium-catalyzed cross-coupling reaction of 1 with 8a. In the presence of $10 \mathrm{~mol} \% \mathrm{Pd}(\mathrm{dba})_{2}$ and $20 \mathrm{~mol}_{\%} \mathrm{PCy}_{3}$, the coupling reaction of 1 with $8 \mathbf{a}$ proceeded at $100{ }^{\circ} \mathrm{C}$, in the absence of any additive, to afford $\mathbf{5 a}$ in $66 \%$ yield. This result pointed out that the reaction takes place even in the absence of a base, while the use of a base is generally indispensible for the Suzuki-Miyaura coupling reaction to enhance the reactivity of organoboron reagents. The addition of $\mathrm{CsCO}_{3}$ did not affect the yield of 5a. Further optimization of the cross-coupling reaction of $\mathbf{1}$ with $\mathbf{8 a}$ was carried out, and as a result, the reaction conducted at $100{ }^{\circ} \mathrm{C}$ in the presence of $\mathrm{Pd}(\mathrm{dba})_{2} / \mathrm{P}^{i} \operatorname{Pr}_{3}$ in THF led to the formation of the desired product 5a in $83 \%$ yield [95].

The optimized reaction conditions were used to investigate the scope of the cross-coupling reaction with arylboronates (Scheme 7). The reactions with 4-anisyl, 4-vinylphenyl, and 4-trifluoromethylphenyl boronates $(\mathbf{8 g}-\mathbf{i})$ also afforded the corresponding trifluorostyrene derivatives $(\mathbf{5 g}-\mathbf{i})$ in good to moderate yields. Of the 4-halogenophenyl boronates employed, 4-fluorophenyl and 4-chlorophenyl boronates yielded $p$-fluoro- and $p$-chloro-substituted ( $\alpha, \beta, \beta$-trifluoro)styrenes (5f and 5j) in $74 \%$ and $76 \%$ yields, respectively. In contrast, no coupling product was generated by employing 4-bromophenyl boronate, probably due to the occurrence of an undesired oxidative addition of the $\mathrm{C}-\mathrm{Br}$ bond. In addition, the reactions with 2- and 1-naphthyl boronates (8n and 8o) gave $\mathbf{5 n}$ and $\mathbf{5 0}$ in $73 \%$ and $88 \%$ yields, respectively. Furthermore, the reaction with 1-pyrenyl boronates $(\mathbf{8 p})$ gave $\mathbf{5 p}$ in moderate yield. The reactions with 2-benzofulyl boronates $(\mathbf{8 q})$ yielded the corresponding products (5q) in moderate yield. Although this catalytic reaction leaves much to be desired regarding the catalyst loading and the product yield, it is of great significance in preparing substituted trifluorostyrenes bearing nitro, aldehyde, ester, and cyano groups $(\mathbf{5 r}-\mathbf{u})$. These functional groups can easily react with Grignard reagents that are required for the in situ preparation of organozinc reagents, and therefore, products $\mathbf{5 r}-\mathbf{u}$ were difficult to synthesize from a coupling reaction with organozinc reagents. In addition, bis-boronate reagents, such as 4,4'-biphenyl diboronate (8v), can be used to prepare monotrifluorovinyl compounds, for which the unreacted boronate moiety was applied in a further cross-coupling reaction to synthesize highly-functionalized derivatives. 
Scheme 7. $\operatorname{Pd}(0)$-catalyzed base-free cross-coupling reaction of 1 with arylboronates $(\mathbf{8})$. General conditions: 8 (1.00 mmol), solvent $(10.0 \mathrm{~mL})$, TFE (3.5 atm). Yields were determined by ${ }^{19} \mathrm{~F}$ NMR analysis of the crude product using $\alpha, \alpha, \alpha$-trifluorotoluene as an internal standard. The values in brackets are of isolated yields. ${ }^{a}$ Using $\mathrm{P}_{n} \mathrm{Bu}_{3}$ instead of $\mathrm{P}_{i} \mathrm{Pr}_{3}$; ${ }^{\mathrm{b}}$ Reaction conditions: 8v $(0.30 \mathrm{mmol})$, solvent $(1.5 \mathrm{~mL})$, TFE (30 mg, $\left.0.30 \mathrm{mmol}\right)$. NMR analysis revealed that $29 \%$ of $\mathbf{8 v}$ was remained and the bistrifluorovinyl compound was generated in $7 \%$ yield; ${ }^{c}$ Reaction conditions: $8 \mathbf{v}(0.95 \mathrm{mmol})$, solvent $(10.0 \mathrm{~mL})$, TFE (100 $\mathrm{mg}, 1.00 \mathrm{mmol})$. After the isolation procedure, $130 \mathrm{mg}(36 \%)$ of $\mathbf{8 v}$ was recovered and the bistrifluorovinyl compound was isolated in $10 \%$ yield.
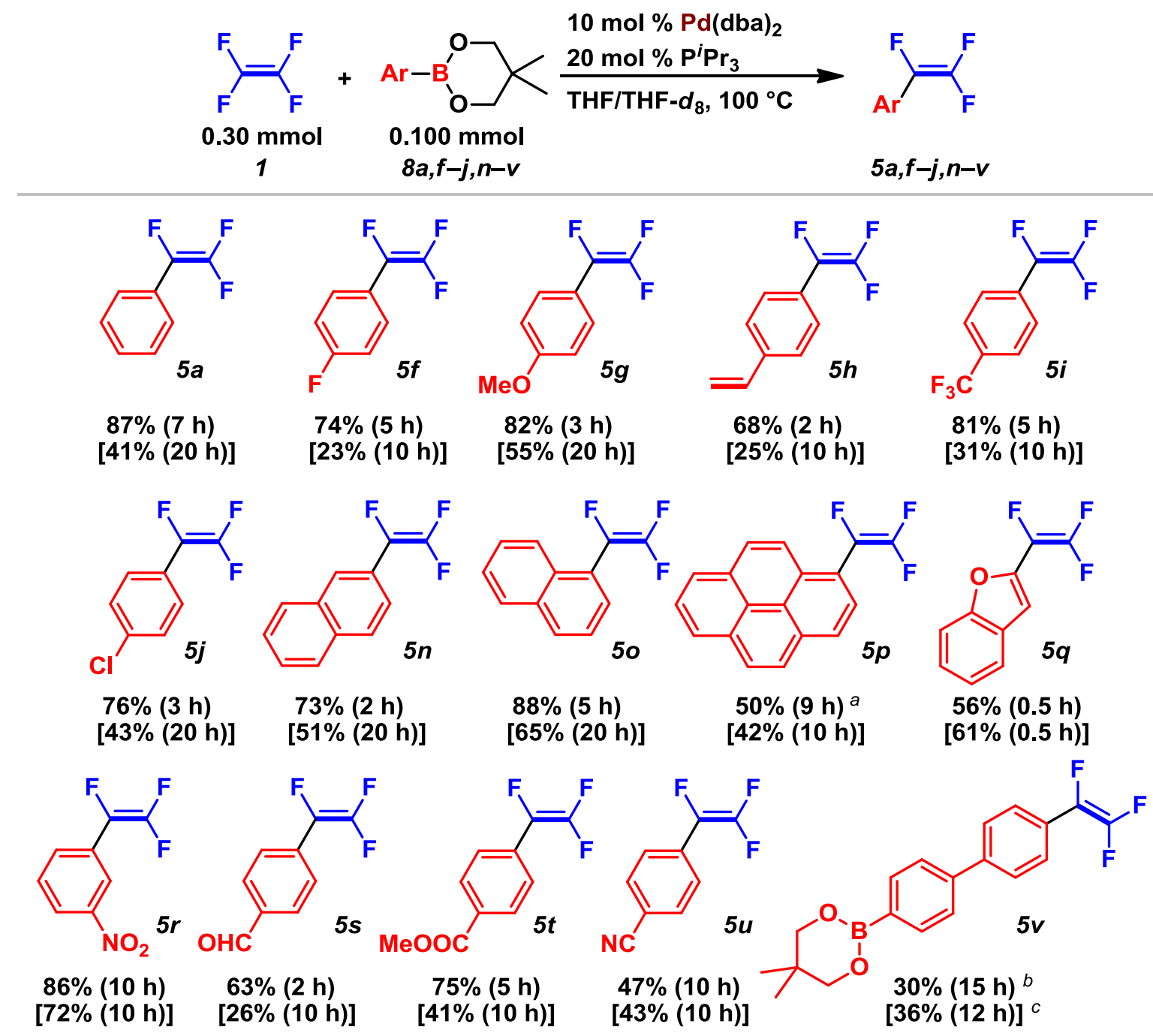

This base-free cross-coupling reaction with arylboronates can be successfully expanded to other organofluorine molecules. The reaction of vinylidene fluoride with $\mathbf{8 0}$ proceeded in the presence of $\operatorname{Pd}(0) / \mathrm{P}^{i} \operatorname{Pr}_{3}$ catalyst, to give 1-(1-fluorovinyl)naphthalene (10o) in $86 \%$ yield (Scheme $\left.8 \mathrm{a}\right)$. In addition, the corresponding reaction with hexafluoropropylene gave a mixture of regioisomers (110) (Scheme 8b), while Dmowski reported the reaction of $\mathrm{CF}_{3} \mathrm{CF}=\mathrm{CF}_{2}$ with $\mathrm{PhMgBr}$ to give an $E / Z$ mixture of $\mathrm{CF}_{3} \mathrm{CF}=\mathrm{CFPh}(E / Z=83 / 17)$ [96]. However, a $\mathrm{Pd}(0)$ catalyst was ineffective in a base-free coupling reaction of fluoroarenes. 
Scheme 8. $\operatorname{Pd}(0)$-catalyzed base-free cross-coupling reactions of (a) vinylidene fluoride or (b) hexafluoropropylene with arylboronates 8o. Yields were determined by ${ }^{19} \mathrm{~F}$ NMR analysis of the crude product using $\alpha, \alpha, \alpha$-trifluorotoluene as an internal standard. The values in brackets are of isolated yields.

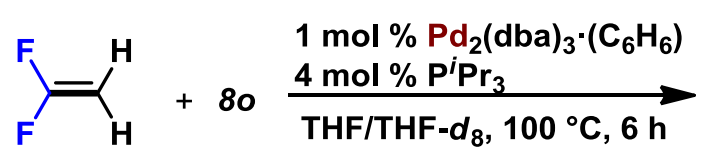

(3.5 atm)

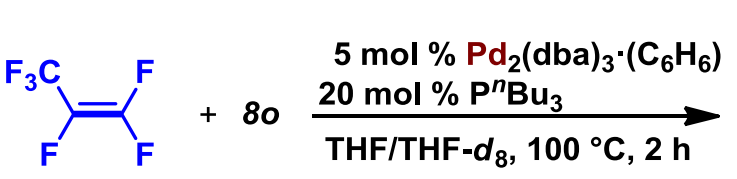

(3.5 atm)

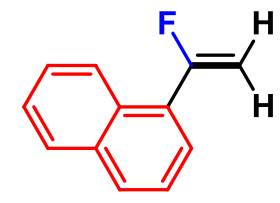

100: $86 \%[85 \%]$

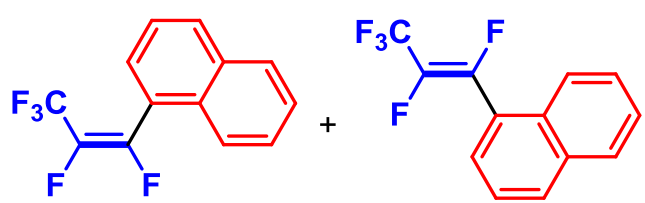

110-cis: $64 \%$ [56\%] 110-trans: $24 \%$ [16\%]

(a)
The base-free Pd-catalyzed monoaryl substitution of $\mathbf{1}$ might proceed as follows (Scheme 9). Coordination of a TFE molecule to $\operatorname{Pd}(0)$ would take place to generate an $\eta^{2}$-TFE species $(\mathbf{A})$. Then, the combination of $\operatorname{Pd}(0)$ and trialkylphosphines with a strong $\sigma$-donor ability would enable the oxidative addition of a $\mathrm{C}-\mathrm{F}$ bond to $\mathrm{Pd}(0)$ with no additives, generating a trifluorovinylpalladium(II) fluoride intermediate (B). The transmetalation of $\mathbf{B}$ with arylboronates [97], would give $\mathbf{C}$, followed by reductive elimination, which would afford $\mathbf{5}$ along with a regeneration of the $\operatorname{Pd}(0)$ species and boronefluorides. Another possible mechanism involving concerted bimolecular elimination via a five-membered transient intermediate could afford 5 [98]. It should be emphasized that no extraneous base is required in this reaction, although extraneous base is generally requisite for the Suzuki-Miyaura cross-coupling reaction to promote a transmetalation step with organoboron reagents.

Scheme 9. A plausible reaction mechanism.

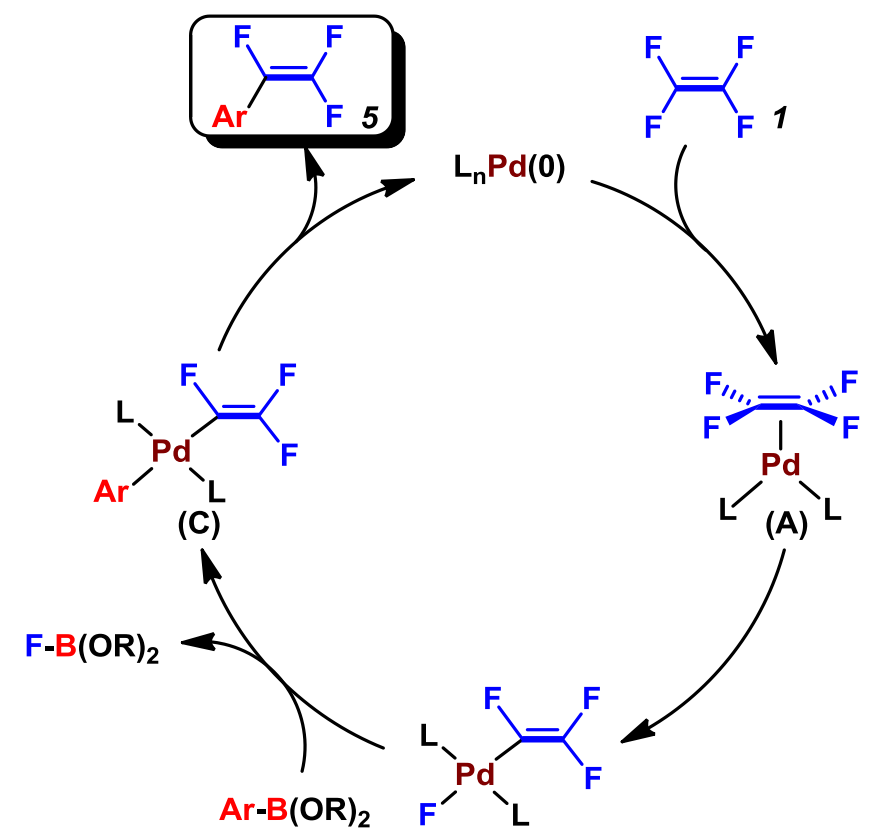

(B) 


\subsection{Pd(0)-Catalyzed Cross-Coupling Reaction of Perfluoroarenes with Diarylzinc Reagents}

Next, we developed the coupling reaction of perfluoroarenes including hexafluorobenzene with diarylzinc compounds, since our methodology suggested the possibility of a cleavage of the unreactive $\mathrm{C}-\mathrm{F}$ bond of $\mathrm{C}_{6} \mathrm{~F}_{6}$ via the cooperation of $\mathrm{Pd}(0)$ and LiI. First, we simply applied the reaction conditions of the coupling reaction of TFE with $\mathrm{Ar}_{2} \mathrm{Zn}$ to the coupling reaction of $\mathrm{C}_{6} \mathrm{~F}_{6}$ (12) with $\mathrm{Ar}_{2} \mathrm{Zn}$ (Table 2). In the presence of $5 \mathrm{~mol} \%$ of $\mathrm{Pd}_{2}(\mathrm{dba})_{3}, 20 \mathrm{~mol}_{\%}$ of $\mathrm{PPh}_{3}$, and 2.5 equiv of LiI at $60{ }^{\circ} \mathrm{C}$ in THF, the reaction of 12 with $4 \mathbf{a}$, prepared in situ by reacting $\mathrm{ZnCl}_{2}$ with 2 equiv of $\mathrm{PhMgBr}$, gave a trace amount of pentafluorophenyl benzene (13a), and the 12 remained intact (entry 1). To promote the oxidative addition of $\mathbf{1 2}$ to palladium, $\mathrm{Pd}\left(\mathrm{PCy}_{3}\right)_{2}$ was examined as a catalyst precursor for the coupling reaction, and $\mathbf{1 3 a}$ was obtained in 70\% yield (entry 2). When isolated $\mathbf{4 a}$ (purchased from Strem) was employed in the coupling reaction, 13a was obtained in $63 \%$ yield (entry 3 ). Because a catalytic reaction using pentafluoroiodobenzene, $\mathrm{C}_{6} \mathrm{~F}_{5} \mathrm{I}$, as a substrate gave only a trace amount of 13a ( $<5 \%$ yield, $70 \%$ S. M. recovered), we ruled out the possibility that $\mathrm{C}_{6} \mathrm{~F}_{5} \mathrm{I}$ could be generated as a result of a nucleophilic attack reaction of iodide anion on 12. In the absence of a palladium catalyst, no coupling product was observed (entry 4). An increase in the amount of LiI improved the yield of 13a to $75 \%$ (entry 5 ), whereas in the absence of LiI, 13a was obtained in 5\% yield even after a prolonged reaction time (entry 6). This result contrasted with that from the reaction of 1 with 4 a generated in situ from $\mathrm{PhMgBr}$ and $\mathrm{ZnCl}_{2}$ (Table 1, entry 1) and indicated that the addition of LiI was crucial for the occurrence of the coupling reaction. In the presence of $\mathrm{PCy}_{3}, \mathrm{Pd}(\mathrm{OAc})_{2}$ was also effective as a catalyst for the coupling reaction (entry 7). A mixture of $\mathrm{Pd}_{2}(\mathrm{dba})_{3}$ and $\mathrm{PCy}_{3}$ (5 and $20 \mathrm{~mol} \%$ each) showed catalytic activity to give $13 \mathrm{a}$ in $77 \%$ yield, while much more catalyst loading $(10 \mathrm{~mol} \% \operatorname{Pd}(0))$ was required for smooth progress in the coupling reaction (entry 8). Employing either DCPE (1,2-dicyclohexylphosphinoethane) or DCPB (1,4-dicyclohexylphosphinobutane) obviously retarded the desired coupling reaction (entries 9 and 10).

Scheme 10 summarizes the results of the $\mathrm{Pd}(0)$-catalyzed cross-coupling reaction of perfluoroarenes with a variety of $\mathrm{Ar}_{2} \mathrm{Zn}$ in the presence of LiI. Both (4-Me- $\left.\mathrm{C}_{6} \mathrm{H}_{4}\right)_{2} \mathrm{Zn}(\mathbf{4 b})$ and $\left(3-\mathrm{Me}-\mathrm{C}_{6} \mathrm{H}_{4}\right)_{2} \mathrm{Zn}(\mathbf{4})$ reacted with 12 to give the corresponding coupling products $(\mathbf{1 3 b}, \mathbf{1 3 c})$ in $70 \%$ and $53 \%$ yields, respectively. In contrast, no coupling reaction product was obtained from the reaction with $\mathrm{Zn}\left(2-\mathrm{Me}-\mathrm{C}_{6} \mathrm{H}_{4}\right)_{2} \quad$ (4d). The reaction with $p$-substituted arylzinc reagents using either an electron-donating or electron-withdrawing group, such as $\mathrm{Zn}\left(4-\mathrm{F}-\mathrm{C}_{6} \mathrm{H}_{4}\right)_{2}$ (4f), $\mathrm{Zn}\left(4-\mathrm{MeO}-\mathrm{C}_{6} \mathrm{H}_{4}\right)_{2}$ (4g), or $\mathrm{Zn}\left(4-\mathrm{Me}_{2} \mathrm{~N}-\mathrm{C}_{6} \mathrm{H}_{4}\right)_{2}$ (4I), afforded the coupling compounds $(\mathbf{1 3 f}, \mathbf{1 3 g}, \mathbf{1 3 I})$ in $66 \%, 76 \%$, and $74 \%$ yields, respectively. When a thienyl group was introduced, the reaction gave 2-pentaphenylthiophene $(\mathbf{1 3 m})$ in $55 \%$ yield. The reaction of 12 with (2-naphthyl) $2 \mathrm{Zn} \mathrm{(4n)} \mathrm{under} \mathrm{the} \mathrm{same} \mathrm{reaction} \mathrm{conditions}$ for $8 \mathrm{~h}$ gave 2-pentafluorophenylnaphthalene (13n) in $65 \%$ yield. The reactions with $\mathrm{Zn}\left(3,5-\mathrm{F}_{2}-\mathrm{C}_{6} \mathrm{H}_{3}\right)_{2}(\mathbf{4 w})$ also yielded the corresponding coupling products (13w) in $49 \%$ yield. Other functionalized aryl zinc species prepared by Knochel's group [99], such as $\mathrm{LiCl} \cdot\left(p-\mathrm{EtCOOC}_{6} \mathrm{H}_{4}\right) \mathrm{ZnI}$ and $\mathrm{LiCl} \cdot\left(p-\mathrm{NCC}_{6} \mathrm{H}_{4}\right) \mathrm{ZnI}$, were successfully applied to the coupling reaction with $\mathrm{C}_{6} \mathrm{~F}_{6}$, giving the corresponding products $(\mathbf{1 3 x}, \mathbf{1 3 y})$ in moderate isolated yields. 
Table 2. Optimization of the catalytic reaction of $\mathrm{C}_{6} \mathrm{~F}_{6}(\mathbf{1 2})$ with $4 \mathrm{a}$ in the presence of $\operatorname{Pd}(0)$ catalyst. Yields were estimated by GC (tetradecane was used as an internal standard).

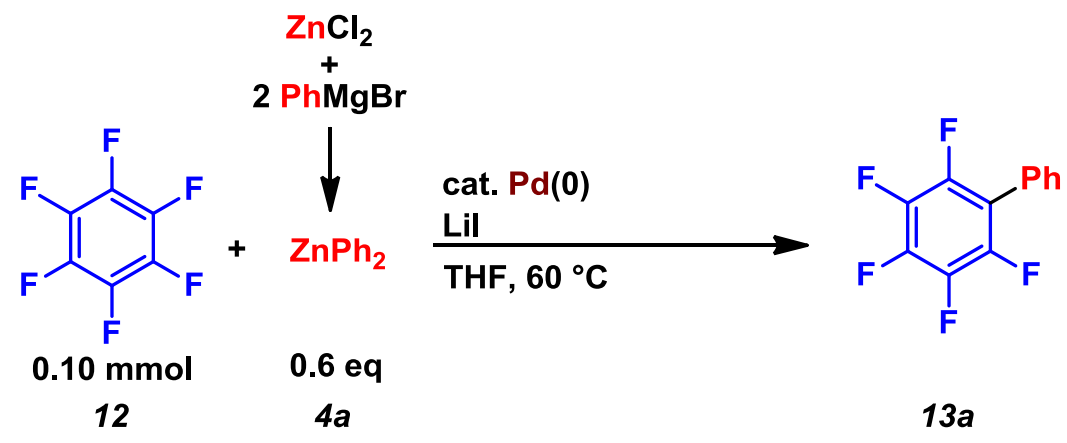

\begin{tabular}{cccccc}
\hline Entry & Catalyst/mol\% & Preparation of $\mathbf{Z n P h} \mathbf{2}(\mathbf{4 a})$ & $\mathbf{L i I} / \mathbf{m m o l}$ & $\mathbf{T i m e} / \mathbf{h}$ & Yield/\% \\
\hline 1 & $\mathrm{Pd}_{2}(\mathrm{dba})_{3}(5) / \mathrm{PPh}_{3}(20)$ & $\mathrm{ZnCl}_{2}+2 \mathrm{PhMgBr}$ & 0.240 & 10 & trace \\
2 & $\mathrm{Pd}\left(\mathrm{PCy}_{3}\right)_{2}(5)$ & $\mathrm{ZnCl}_{2}+2 \mathrm{PhMgBr}$ & 0.240 & 4 & 70 \\
3 & $\mathrm{Pd}\left(\mathrm{PCy}_{3}\right)_{2}(10)$ & isolated $\mathrm{ZnPh}_{2}$ & 0.200 & 4 & 63 \\
4 & - & $\mathrm{ZnCl}_{2}+2 \mathrm{PhMgBr}$ & 0.240 & 21 & - \\
5 & $\mathrm{Pd}\left(\mathrm{PCy}_{3}\right)_{2}(5)$ & $\mathrm{ZnCl}_{2}+2 \mathrm{PhMgBr}$ & 0.360 & 6 & 75 \\
6 & $\mathrm{Pd}\left(\mathrm{PCy}_{3}\right)_{2}(5)$ & $\mathrm{ZnCl}_{2}+2 \mathrm{PhMgBr}$ & - & 10 & 5 \\
$7^{a}$ & $\mathrm{Pd}(\mathrm{OAc})_{2}(5) / \mathrm{PCy}(10)$ & $\mathrm{ZnCl}_{2}+2 \mathrm{PhMgBr}$ & 0.240 & 4 & 65 \\
8 & $\mathrm{Pd}(\mathrm{dba})_{3}(5) / \mathrm{PCy}(20)$ & $\mathrm{ZnCl}_{2}+2 \mathrm{PhMgBr}$ & 0.360 & 4 & 77 \\
$9^{a}$ & $\mathrm{Pd}(\mathrm{OAc})_{2}(5) / \mathrm{DCPE}(5)$ & $\mathrm{ZnCl}_{2}+2 \mathrm{PhMgBr}$ & 0.240 & 9 & 13 \\
$10^{a}$ & $\mathrm{Pd}(\mathrm{OAc})_{2}(5) / \mathrm{DCPB}(5)$ & $\mathrm{ZnCl}_{2}+2 \mathrm{PhMgBr}$ & 0.240 & 15 & trace \\
\hline
\end{tabular}

${ }^{\mathrm{a}} 0.7$ equiv of $4 \mathbf{a}$ was employed.

The reaction was applicable to other perfluoroarenes. The coupling reaction of octafluorotoluene $\left(\mathrm{C}_{7} \mathrm{~F}_{8} ; \mathbf{1 4}\right)$ with $\mathbf{4 a}, \mathbf{4 d}$, and $\mathbf{4 g}$ took place at the 4-position of $\mathbf{1 4}$ to give the corresponding products (15a, 15d, 15g) in good to excellent yields. In particular, the reaction of 14 with $\mathbf{4 g}$ proceeded very smoothly, which allowed the confirmation of a back-ground reaction. In the absence of $\operatorname{Pd}\left(\mathrm{PCy}_{3}\right)_{2}$, 15g was obtained in $30 \%$ yield at $60^{\circ} \mathrm{C}$ for $6 \mathrm{~h}$, which indicated that the palladium-catalyzed coupling reaction proceeded much faster than the background reaction. The use of perfluoronaphthalene (16) and perfluorobiphenyl (17) allowed the reaction with $\mathbf{4 g}$ to give 2-(4- $\left.\mathrm{MeOC}_{6} \mathrm{H}_{4}\right) \mathrm{C}_{10} \mathrm{~F}_{7}(\mathbf{1 8 g})$ and 4'-(4- $\left.\mathrm{MeOC}_{6} \mathrm{H}_{4}\right) \mathrm{C}_{12} \mathrm{~F}_{9}(\mathbf{1 9 g})$ in $53 \%$ and $32 \%$ yields, respectively. In contrast, the reaction of perfluoropyridine (20) with $\mathbf{4 a}$ afforded a mixture of tetrafluoro-4-phenylpyridine (21a) and tetrafluoro-2-phenylpyridine (21a') in 65\% and 17\% yields, respectively. Pentafluorobenzene (22) also successfully participated in the coupling reaction with $\mathbf{4 a}$; however, the reaction product was obtained as a mixture of two regioisomers, 2,3,4,5-tetrafluorobiphenyl (23a) and 2,3,5,6-tetrafluorobiphenyl (23a'), and the combined yield of the coupling product was only $38 \%$. 
Scheme 10. $\mathrm{Pd}(0)$-catalyzed base-free cross-coupling reaction of $\mathbf{1}$ with arylboronates $(\mathbf{8})$. General conditions: $\mathrm{Pd}\left(\mathrm{PCy}_{3}\right)_{2}(0.05 \mathrm{mmol}), 4(0.60 \mathrm{mmol})$, LiI $(2.40 \mathrm{mmol})$, solvent $(5.0 \mathrm{~mL})$, perfluroarenes $(1.00 \mathrm{mmol})$.

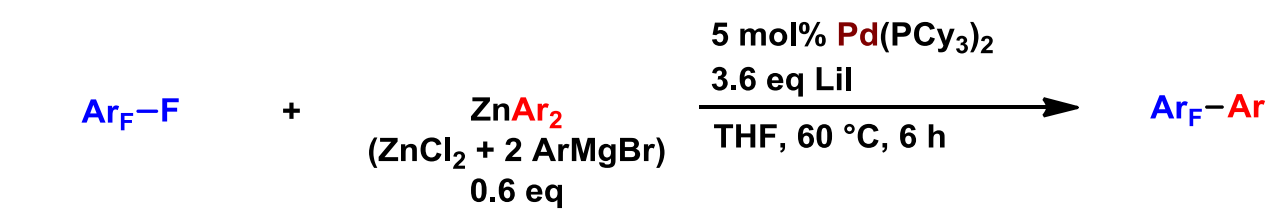

$$
\begin{aligned}
\operatorname{Ar}_{\mathrm{F}}= & \mathrm{C}_{6} \mathrm{~F}_{5}(12) \\
& 4-\mathrm{CF}_{3}-\mathrm{C}_{6} \mathrm{~F}_{4}(14) \\
& 2-\mathrm{C}_{10} \mathrm{~F}_{7}(16) \\
& 4-\mathrm{C}_{6} \mathrm{~F}_{5}-\mathrm{C}_{6} \mathrm{~F}_{4}(17) \\
& \mathrm{C}_{5} \mathrm{~F}_{4} \mathrm{~N}(20) \\
& \mathrm{C}_{6} \mathrm{~F}_{4} \mathrm{H}(22)
\end{aligned}
$$

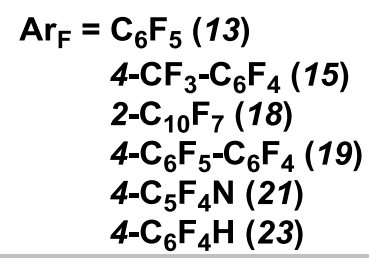<smiles>Fc1c(F)c(F)c(-c2ccccc2)c(F)c1F</smiles>

13a: $69 \%$<smiles>Cc1ccc(-c2c(F)c(F)c(F)c(F)c2F)cc1</smiles>

13b: $70 \%$<smiles>Cc1cccc(-c2c(F)c(F)c(F)c(F)c2F)c1</smiles>

13c: $53 \%$<smiles>Fc1ccc(-c2c(F)c(F)c(F)c(F)c2F)cc1</smiles>

$13 f: 66 \%$<smiles>COc1ccc(-c2c(F)c(F)c(F)c(F)c2F)cc1</smiles>

13g: $74 \%$<smiles>CN(C)c1ccc(-c2c(F)c(F)c(F)c(F)c2F)cc1</smiles>

13I: $76 \%$<smiles>Fc1c(F)c(F)c(-c2cccs2)c(F)c1F</smiles>

13m: $55 \%$<smiles>Fc1c(F)c(F)c(-c2ccc3ccccc3c2)c(F)c1F</smiles>

$13 n$ : $65 \%$<smiles>Fc1cc(F)cc(-c2c(F)c(F)c(F)c(F)c2F)c1</smiles>

13w: $49 \%$<smiles>Cc1ccccc1-c1c(F)c(F)c(C(F)(F)F)c(F)c1F</smiles>

15d: $60 \%$<smiles>CCOC(=O)c1ccc(-c2c(F)c(F)c(F)c(F)c2F)cc1</smiles>

13x: $57 \%$<smiles>N#Cc1ccc(-c2c(F)c(F)c(F)c(F)c2F)cc1</smiles>

13y: $49 \%$<smiles>Fc1c(F)c(C(F)(F)F)c(F)c(F)c1-c1ccccc1</smiles>

15a: $65 \%$<smiles>COc1ccc(-c2c(F)c(F)c(C(F)(F)F)c(F)c2F)cc1</smiles>

15g: $92 \%$<smiles></smiles><smiles>Fc1cc(F)c(F)c(-c2ccccc2)c1F</smiles>

To gain deeper insight into the reaction mechanism, stoichiometric reactions of 12 with $\operatorname{Pd}(0)$ complexes were carried out. In a previous report by Grushin, the reaction of 12 with $\mathrm{Pd}\left(\mathrm{PCy}_{3}\right)_{2}$ in $\mathrm{THF}$ 
at $70{ }^{\circ} \mathrm{C}$ for $24 \mathrm{~h}$ proceeded very slowly to yield a perfluorophenylpalladium(II) fluoride, trans- $(\mathrm{PCy})_{2} \mathrm{Pd}(\mathrm{F})\left(\mathrm{C}_{6} \mathrm{~F}_{5}\right)$, in 3\% yield [93]. In the presence of LiI, on the other hand, the oxidative addition took place much faster to give a perfluorophenylpalladium(II) iodide, trans- $\left(\mathrm{PCy}_{3}\right)_{2} \mathrm{Pd}(\mathrm{I})\left(\mathrm{C}_{6} \mathrm{~F}_{5}\right)$ (24), which indicated that an important role of lithium iodide was to accelerate the oxidative addition (Scheme 11a). Although the catalytic reaction of $\mathbf{1 2}$ with $\mathbf{4 a}$ occurred in the presence of $\operatorname{Pd}_{2}(\mathrm{dba})_{3}$ and 4 equiv of $\mathrm{PCy}_{3}$ to give 13a in $77 \%$ yield (Table 2, entry 7 ), an oxidative addition did not occur in the presence of DBA in the stoichiometric reaction at $60{ }^{\circ} \mathrm{C}$ (Scheme 11b). This result might have been due to an inhibition of the coordination of $\mathrm{C}_{6} \mathrm{~F}_{6}$ to palladium by DBA under the stoichiometric reaction conditions and could indicate why $\mathrm{Pd}\left(\mathrm{PCy}_{3}\right)_{2}$ is a more efficient catalyst than the combination of $\mathrm{Pd}_{2}(\mathrm{dba})_{3}$ and $\mathrm{PCy}_{3}$. In stark contrast, even in the presence of LiI, the oxidative addition of $\mathrm{C}_{6} \mathrm{~F}_{6}$ to $\operatorname{Pd}\left(\mathrm{PPh}_{3}\right)_{4}$ did not occur, which is consistent with the observation that no reaction occurred in the presence of $\mathrm{PPh}_{3}$ (Table 2, entry 1). The ORTEP diagram of 24 definitely shows that the palladium in 24 adopts a square-planar coordination geometry and is coordinated with two $\mathrm{PCy}_{3}$ ligands in a trans manner (Figure 2). A similar coordination geometry was observed in structurally well-defined $\mathrm{Pd}(\mathrm{II})$ complexes, such as trans- $\left(\mathrm{PPh}_{3}\right)_{2} \mathrm{Pd}(\mathrm{Cl})\left(\mathrm{C}_{6} \mathrm{~F}_{5}\right)$ and trans- $\left(\mathrm{PCy}_{2} R\right)_{2} \mathrm{Pd}(\mathrm{I})\left(\mathrm{C}_{6} \mathrm{~F}_{5}\right)$ ( $R=$ ferrocenyl group) $[100,101]$.

Scheme 11. Stoichiometric Reactions of 12 with (a) $\mathrm{Pd}\left(\mathrm{PCy}_{3}\right)_{2}$ or (b) a mixture of $\mathrm{Pd}_{2}(\mathrm{dba})_{3}$ and $\mathrm{PCy}_{3}$ in the Presence of LiI.

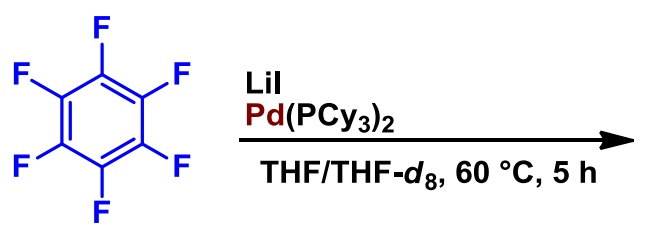

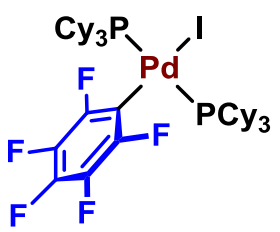

12

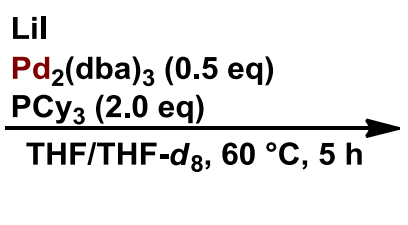

12
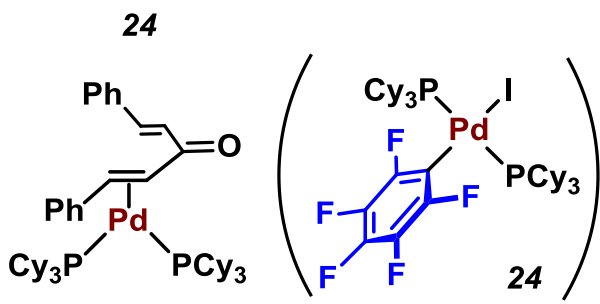

not detected

Figure 2. Molecular structure of $\mathbf{2 4}$ with thermal ellipsoids at the $30 \%$ probability level. $\mathrm{H}$ atoms are omitted for clarity.

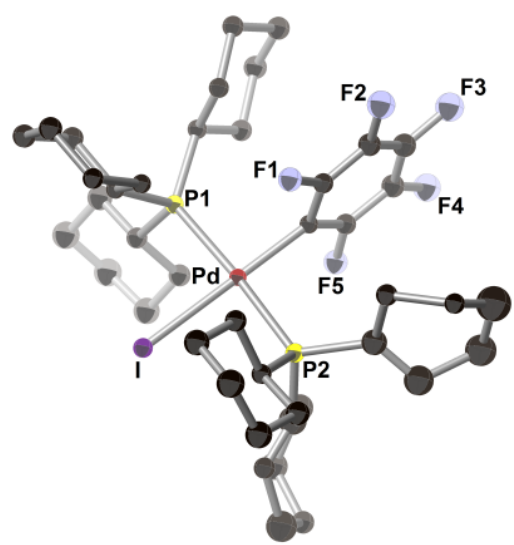


To confirm whether $\mathbf{2 4}$ is an intermediate in the $\operatorname{Pd}(0)$-catalyzed cross-coupling reaction of 12 with diarylzinc or not, a stoichiometric reaction of $\mathbf{2 4}$ with $\mathbf{4 a}$ was also carried out. As a result, only a yield of $5 \%$ of $13 \mathrm{a}$ was obtained from a stoichiometric reaction conducted at $60{ }^{\circ} \mathrm{C}$ for $7 \mathrm{~h}$ in the presence of an excess amount of LiI, whereas 13a was obtained under the catalytic reaction conditions mentioned above $\left(60{ }^{\circ} \mathrm{C}\right.$ for $6 \mathrm{~h}$; Scheme 10). This result strongly indicates that $\mathbf{2 4}$ is an unlikely reaction intermediate due to the steric hindrance around the palladium center caused by the two bulkier $\mathrm{PCy}_{3}$ ligands. Thus, we assumed that the oxidative addition of $\mathrm{C}_{6} \mathrm{~F}_{6}$ to $\mathrm{Pd}\left(\mathrm{PCy}_{3}\right)_{2}$ in the presence of LiI might involve a dissociation process of the $\mathrm{PCy}_{3}$ ligand to give a transient species, $\left(\mathrm{PCy}_{3}\right) \mathrm{Pd}\left(\mathrm{C}_{6} \mathrm{~F}_{5}\right)(\mathrm{I})$. The resultant 3-coordinated transient intermediate would undergo re-coordination of a $\mathrm{PCy}_{3}$ ligand in the absence of $\mathbf{4 a}$ to yield the thermodynamically favored, and unreactive $\mathbf{2 4}$. On the other hand, in the presence of $\mathbf{4 a}$, transmetalation between the transient iodopalladium(II) species and $\mathbf{4 a}$ took place smoothly to give the coupling product 13a. These assumptions are consistent with the results from Hartwig's kinetic studies wherein the oxidative addition of chlorobenzene to $\mathrm{Pd}\left(\mathrm{PCy}_{3}\right)_{2}$, giving trans- $(\mathrm{PCy})_{2} \mathrm{Pd}(\mathrm{Ph})(\mathrm{Cl})$, involved the dissociation process of a $\mathrm{PCy}_{3}$ ligand at the initial stage of the reaction [102]. Unfortunately, any attempt to prepare the transient intermediate failed due to its coordinative unsaturation, and therefore, $c i s-\left(\mathrm{C}_{6} \mathrm{~F}_{5}\right) \mathrm{Pd}(\mathrm{I})(\mathrm{py})\left(\mathrm{PCy}_{3}\right)(\mathbf{2 5})$, in which pyridine acts as a labile ligand to generate a tentative 3-coordinate $\left(\mathrm{PCy}_{3}\right) \mathrm{Pd}\left(\mathrm{C}_{6} \mathrm{~F}_{5}\right)(\mathrm{I})$ species, was prepared as an alternative catalytic precursor.

Scheme 12 summarizes the synthetic route to the preparation of 25 . The reaction of $\left(\mathrm{C}_{6} \mathrm{~F}_{5}\right)_{2} \mathrm{Pd}(\mathrm{Py})_{2}$ (26) with $\mathrm{PdCl}_{2}$ in acetone $[103,104]$ followed by treatment with $\mathrm{PCy}_{3}$ in pyridine resulted in the formation of cis- $\left(\mathrm{C}_{6} \mathrm{~F}_{5}\right)(\mathrm{Cl}) \mathrm{Pd}(\mathrm{Py})\left(\mathrm{PCy}_{3}\right)(27)$ in $32 \%$ yield. Substitution of an iodide for the chloride ligand in $\mathbf{2 7}$ was accomplished by treating an acetone solution of $\mathbf{2 7}$ with an excess amount of NaI, giving the desired palladium(II) iodide $\mathbf{2 5}$ in 55\% yield. The novel pentafluorophenyl palladium(II) iodide 25 was characterized on the basis of NMR spectroscopy and elemental analysis, as well as $\mathrm{X}$-ray diffraction analysis. Both pyridine and $\mathrm{PCy}_{3}$ ligands in $\mathbf{2 5}$ were situated in a mutual cis position with a square-planar Pd(II) geometry, as shown by X-ray diffraction (Figure 3).

Scheme 12. Preparation of cis- $\left(\mathrm{C}_{6} \mathrm{~F}_{5}\right) \mathrm{Pd}(\mathrm{I})(\mathrm{py})\left(\mathrm{PCy}_{3}\right)(25)$.

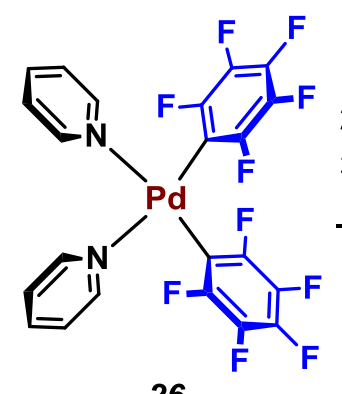

26
1) 1.1 eq $\mathrm{PdCl}_{2}$ in acetone, reflux, $3 \mathrm{~h}$

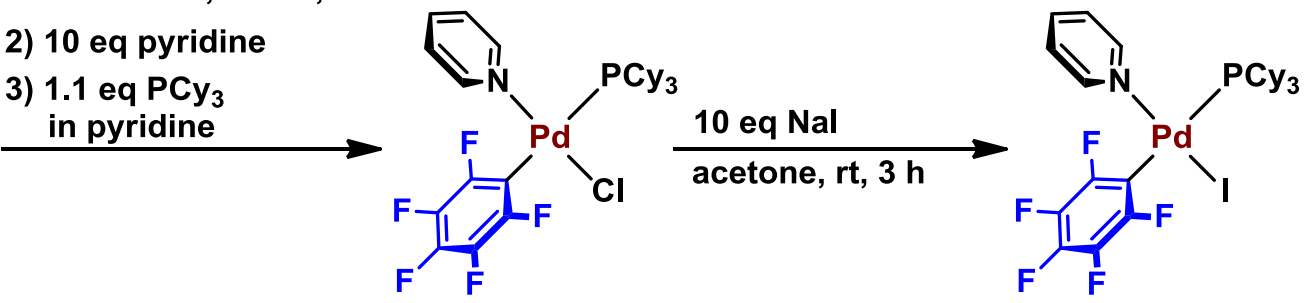

27 (32\%)

$25(55 \%)$

We then evaluated the reactivity of $\mathbf{2 5}$ toward $\mathbf{4 a}$ in the presence or absence of lithium iodide. In the presence of LiI (1.5 equivalent), 25 reacted smoothly with $\mathbf{4 a}$, which was carefully purified by sublimation prior to use, in THF at room temperature to afford 13a in $63 \%$ yield as a sole product (Scheme 13). The addition of $\mathrm{PCy}_{3}$ to this reaction mixture affected neither the yield nor the selectivity of the reaction product. On the other hand, in the absence of LiI, the reaction of $\mathbf{2 5}$ with $\mathbf{4 a}$ under the 
same reaction conditions afforded a pentafluorophenylzinc species, $\mathrm{C}_{6} \mathrm{~F}_{5} \mathrm{Zn} X\left(X=\mathrm{I}\right.$ or $\left.\mathrm{C}_{6} \mathrm{~F}_{5}\right)$, as a major product (54\%), and 13a was concomitantly obtained as a minor product in $27 \%$ yield. These observations suggest the following: (a) a transient $\left(\mathrm{PCy}_{3}\right) \mathrm{Pd}\left(\mathrm{C}_{6} \mathrm{~F}_{5}\right)(\mathrm{I})$ species, generated via dissociation of the labile pyridine ligand of $\mathbf{2 5}$, could be crucial for the smooth occurrence of transmetalation between the palladium(II) species and $\mathbf{4 a}$, and (b) the existence of LiI is essential for selective transmetalation to generate 13a.

Figure 3. Molecular structure of $\mathbf{2 5}$ with thermal ellipsoids at the $30 \%$ probability level. $\mathrm{H}$ atoms are omitted for clarity.

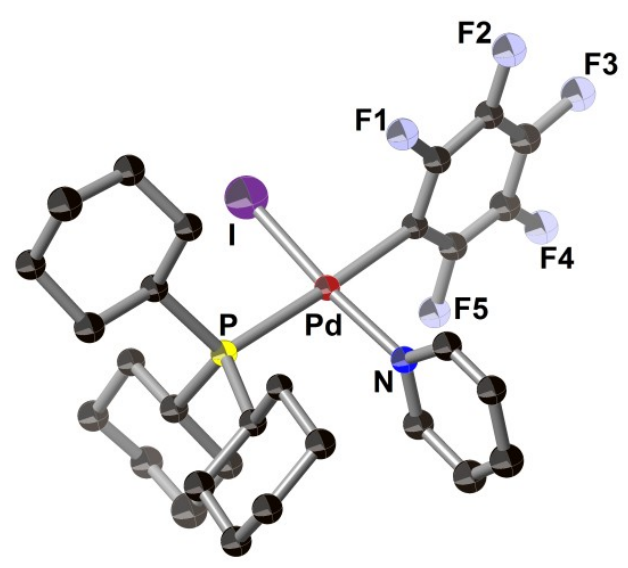

Scheme 13. Stoichiometric Reactions of 25 with $4 \mathbf{a}$ in the presence or absence of LiI.

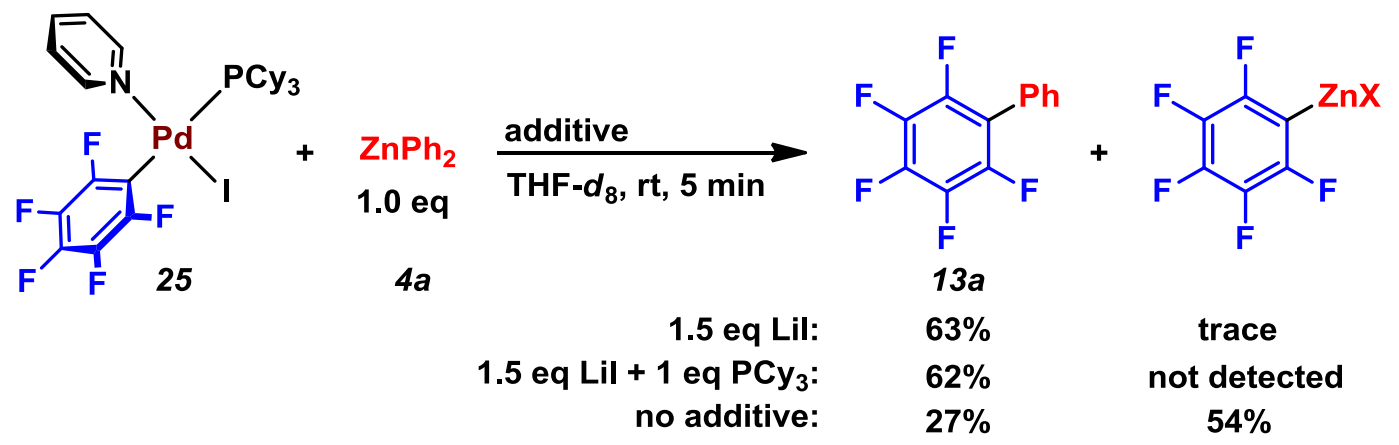

Based on those results, a plausible reaction mechanism was proposed, as shown in Scheme 14. In the presence of LiI, the oxidative addition of the $\mathrm{C}-\mathrm{F}$ bond in $\mathbf{1 2}$ to $\mathrm{Pd}(0)$ would occur by dissociation of a $\mathrm{PCy}_{3}$ ligand, forming a $\left(\mathrm{C}_{6} \mathrm{~F}_{5}\right)(\mathrm{I}) \mathrm{Pd}\left(\mathrm{PCy}_{3}\right)$ intermediate $(\mathbf{A})$. We speculate that the LiI-promoted $\mathrm{C}-\mathrm{F}$ bond activation of $\mathbf{1 2}$ on $\mathrm{Pd}\left(\mathrm{PCy}_{3}\right)_{2}$ would take place to give the cis-oxidative addition product, and the rapid dissociation of a $\mathrm{PCy}_{3}$ ligand then might occur due to the steric hindrance of the two bulkier $\mathrm{PCy}_{3}$ ligands. On the basis of theoretical and experimental studies, Radius et al. assumed that a related $\mathrm{C}-\mathrm{F}$ bond activation of $\mathbf{1 2}$ on a $\mathrm{Ni}(\mathrm{NHC})_{2}$ fragment, yielding trans-[Ni( $\left.\left.\mathrm{NHC}\right)_{2}\left(\mathrm{C}_{6} \mathrm{~F}_{5}\right)(\mathrm{F})\right]$, would proceed via the corresponding cis-oxidative addition product [61]. Transmetalation between $\mathbf{A}$ and $\mathbf{4}$ in the presence of LiI would take place to give a biarylpalladium(II) intermediate (B). This transmetalation step would progress in preference to the re-coordination of a $\mathrm{PCy}_{3}$ ligand, giving an unreactive trans-( $\left.\mathrm{PCy}_{3}\right)_{2} \mathrm{Pd}\left(\mathrm{C}_{6} \mathrm{~F}_{5}\right)(\mathrm{I})\left(\mathbf{A}^{\prime}\right)$. The role of LiI in this reaction step might be rationalized by the formation of a reactive zincate such as $\mathrm{Li}[\mathrm{ArZn} X \mathrm{I}](X=\mathrm{Ar}$ or I) that would enable the efficient 
formation of $\mathbf{B}[41,68]$. Then, reductive elimination from $\mathbf{B}$ followed by the re-coordination of a $\mathrm{PCy}_{3}$ ligand would yield the coupling product along with a regeneration of the $\operatorname{Pd}(0)$ species. Another possible route for the coupling reaction might involve the formation of a dimer intermediate $\left[\left(\mathrm{PCy}_{3}\right) \mathrm{Pd}\left(\mathrm{C}_{6} \mathrm{~F}_{5}\right)(\mu-\mathrm{I})\right]_{2}$. Hor argued for the possibility that both catalytic pathways, via mononuclear cis/trans geometric isomers and a dinuclear iodide-bridged intermediate, might contribute to the $\operatorname{Pd}(0)$-catalyzed coupling reaction of pentafluorophenyl iodide with phenylboronic acid [101].

Scheme 14. A plausible reaction mechanism.

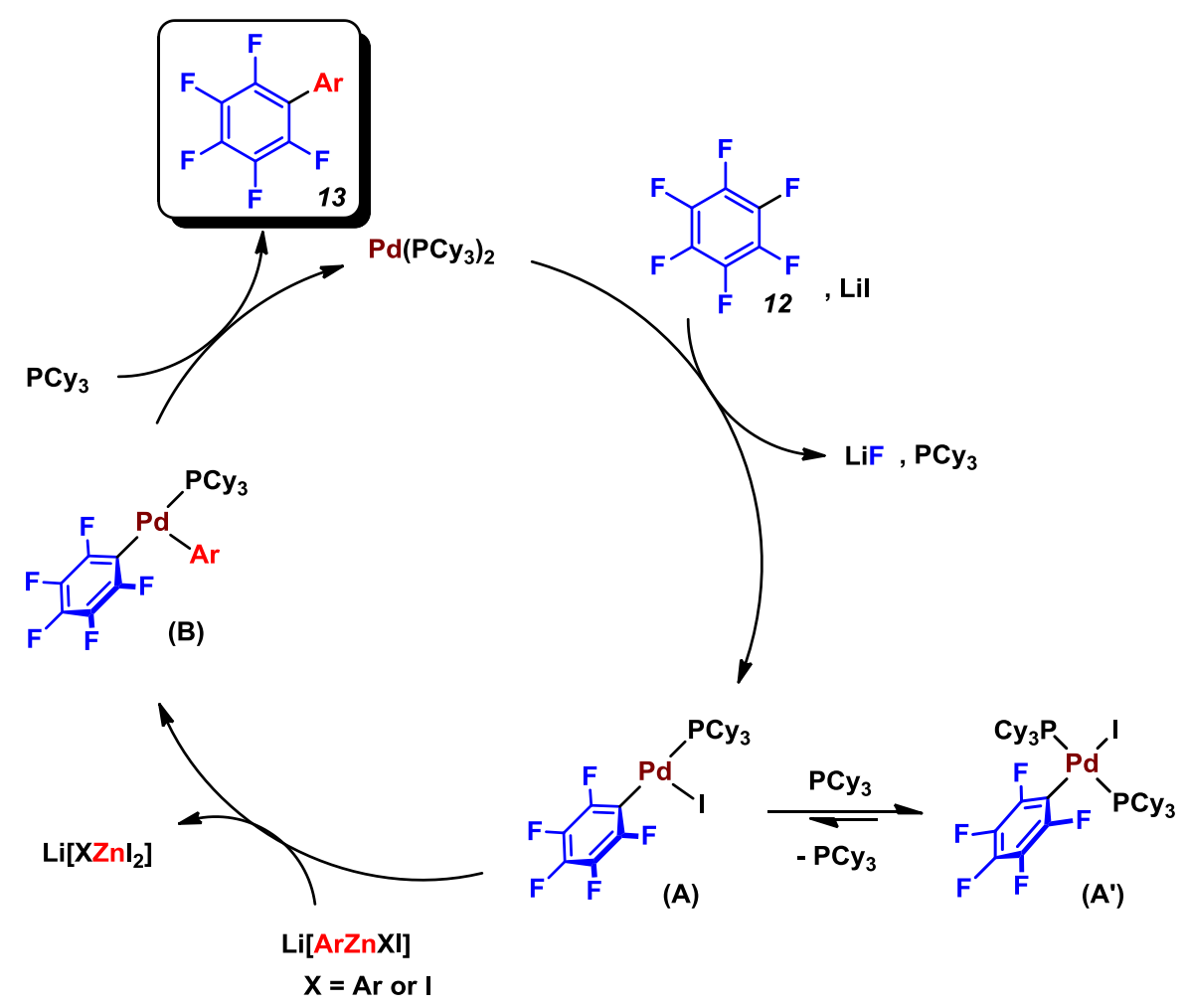

\section{Conclusions}

In this review, we reported recent results for a palladium-catalyzed cross-coupling reaction of perfluoroorganic compounds with organometallic reagents. We have developed the first palladium-catalyzed monoarylation of TFE by employing in situ-prepared diarylzinc reagents to yield ( $\alpha, \beta, \beta$-trifluoro)styrene derivatives in excellent yield and with high selectivity. C-F bond activation of TFE was achieved by the synergetic effects of the palladium(0) species and LiI to generate the trifluorovinyl palladium(II) intermediate.

We also demonstrated the $\mathrm{Pd}(0) / \mathrm{PR}_{3}$-catalyzed cross-coupling reaction of TFE with arylboronate. This reaction required neither an extraneous base to enhance the reactivity of organoboronates nor a Lewis acid additive to promote the oxidative addition of a $\mathrm{C}-\mathrm{F}$ bond. The key palladium(II) fluoride intermediate that showed a unique reactivity toward organoboron compounds was isolated. These results may open new avenues for the development of a base-free Suzuki-Miyaura coupling reaction including the in situ generation of a metal fluoride intermediate via $\mathrm{C}-\mathrm{F}$ bond activation. Furthermore, our development of palladium-catalyzed selective transformations of TFE via $\mathrm{C}-\mathrm{F}$ bond activation greatly increases the potential of $\mathbf{1}$ as a useful starting material for a variety of organofluorine compounds. 
In addition, we developed a $\mathrm{Pd}(0) / \mathrm{PCy}_{3}$-catalyzed cross-coupling reaction using $\mathrm{C}_{6} \mathrm{~F}_{6}$ with a variety of diarylzinc compounds to give the corresponding pentafluorobiaryls in good to excellent yields. Stoichiometric reactions employing model complexes, trans- $(\mathrm{PCy})_{2} \mathrm{Pd}(\mathrm{I})\left(\mathrm{C}_{6} \mathrm{~F}_{5}\right)$ and cis- $\left(\mathrm{C}_{6} \mathrm{~F}_{5}\right) \mathrm{Pd}(\mathrm{I})(\mathrm{py})\left(\mathrm{PCy}_{3}\right)$, with diphenylzinc in the presence of lithium iodide revealed both the catalytic reaction mechanism and the role of lithium iodide in this catalytic reaction. The key intermediate in this catalytic cycle was a transient 3-coordinated, monophosphine-ligated species, $\left(\mathrm{PCy}_{3}\right) \mathrm{Pd}\left(\mathrm{C}_{6} \mathrm{~F}_{5}\right)(\mathrm{I})$, which was generated by the oxidative addition of the $\mathrm{C}-\mathrm{F}$ bond of $\mathrm{C}_{6} \mathrm{~F}_{6}$ to $\mathrm{Pd}\left(\mathrm{PCy}_{3}\right)_{2}$ followed by the dissociation of a $\mathrm{PCy}_{3}$ ligand. In this catalytic reaction, lithium iodide accelerated the oxidative addition step and generated a reactive zincate such as $\operatorname{Li}[\mathrm{ArZn} X \mathrm{I}](X=\mathrm{Ar}$ or I) that enabled an efficient transmetalation with the key intermediate. We have also described how this catalytic reaction could be applied to other monocyclic perfluorinated compounds, such as octafluorotoluene and pentafluoropyridine, as well as to polycyclic perfluorinated compounds, such as perfluoronaphthalene and perfluorobiphenyl, to give the corresponding coupling products.

\section{Acknowledgments}

This work was supported by a Grant-in-Aid for Scientific Research (A) (No. 21245028), a Grant-in-Aid for Young Scientists (A) (No. 25708018), and a Grant-in-Aid for Scientific Research on Innovative Areas "Molecular Activation Directed toward Straightforward Synthesis" (No. 23105546) from MEXT. Masato Ohashi also acknowledges The Noguchi Institute.

\section{Author Contributions}

Masato Ohashi wrote the first draft of the manuscript that was then improved by Sensuke Ogoshi. The literature was researched by both of the authors.

\section{Conflicts of Interest}

The authors declare no conflict of interest.

\section{References and Notes}

1. Banks, R.E.; Sharp, D.W.A.; Tatlow, J.C. Fluorines-The First Hundred Years (1886-1986); Elsevier: New York, NY, USA, 1986.

2. Banks, R.E.; Smart, B.E.; Tatlow, J.C. Organofluorine Chemistry: Principles and Commercial Applications; Plenum Press: New York, NY, USA, 2000.

3. Filler, R.; Kobayashi, Y.; Yagupolskii, L.N. Organofluorine Compounds in Medicinal and Biomedical Applications; Elsevier: Amsterdam, The Netherlands, 1993.

4. Ojima, I.; MaCaethy, J.R.; Welch, J.T. Biomedical Frontiers of Fluorine Chemistry; American Chemical Society: Washington, DC, USA, 1996.

5. Hiyama, T.; Kanie, K.; Kusumoto, T.; Morizawa, Y.; Shimizu, M. Organofluorine Compounds: Chemistry and Application; Springer-Verlag: Berlin, Germany, 2000.

6. Kirsh, P. Modern Fluoroorganic Chemistry; Wiley-VCH: Weinheim, Germany, 2004.

7. Chambers, R.D. Fluorine in Organic Chemistry; Blackwell: Oxford, UK, 2004. 
8. Uneyama, K. Organofluorine Chemistry; Blackwell: Oxford, UK, 2006.

9. Bégué, J.-P.; Bonnet-Delpon, D. Bioorganic and Medicinal Chemistry of Fluorine; John Wiley \& Sons, Inc.: Hoboken, NJ, USA, 2008.

10. Souzy, R.; Ameduri, B.; Boutevin, B. Synthesis and (co)polymerization of monofluoro, difluoro, trifluorostyrene and ((trifluorovinyl)oxy)benzene. Prog. Polym. Sci. 2004, 29, 75-106.

11. Souzy, R.; Ameduri, B.; Boutevin, B.; Gebel, G.; Capron, P. Functional fluoropolymers for fuel cell membranes. Solid State Ion. 2005, 176, 2839-2848.

12. Hougham, G.; Cassidy, P.E.; Johns, K.; Davidson, T. Fluoropolymers 1: Synthesis in Topics in Applied Chemistry; Kluwer Academic/Plenum Publisher: New York, NY, USA, 2002.

13. Cohen, S.G.; Wolosinski, H.T.; Scheuer, P.J. $\alpha, \beta, \beta$-trifluorostyrene and $\alpha$-Chloro- $\beta, \beta$-difluorostyrene. J. Am. Chem. Soc. 1949, 71, 3439-3440.

14. Prober, M. The Synthesis and Polymerization of Some Fluorinated Styrenes. J. Am. Chem. Soc. 1953, 75, 968-973.

15. Dvornikova, K.V.; Platonov, V.E.; Yakobson, G.G. Thermolytic transformations of polyfluoroorganic compounds XXIX. Formation of fluorine-containing styrenes by reactions of benzotrichloride and related compounds with dihalocarbene sources. J. Fluor. Chem. 1985, 28, 99-113.

16. Anilkumar, R.; Burton, D.J. A highly efficient room temperature non-organometallic route for the synthesis of $\alpha, \beta, \beta$-trifluorostyrenes by dehydrohalogenation. Tetrahedron Lett. 2003, 44, 6661-6664.

17. Dixon, S. Elimination Reaction of Fluoroölefines with Organolithium Compounds. J. Org. Chem. 1956, 21, 400-403.

18. Tarrant, P.; Heyes, J. Fluoro Olefins. XII. The Reaction of Allylmagnesium Bromide with Fluoro Olefins. J. Org. Chem. 1965, 30, 1485-1487.

19. Jiang, X.; Wu, C.; Wu, Z. Chemistry of trifluorostyrenes and their dimmers. Acta Chem. Sin. 1983, 1, 42-49.

20. Sigalov, A.B.; Rybakova, L.F.; Beletskaya, I.P. Arylation of fluoroolefins by phenyl derivatives of ytterbium(II) and europium(II). Izv. Akad. Nauk. SSSR Ser. Khim. 1983, 1208.

21. Sigalov, A.B.; Beletskaya, I.P. Reactions of phenyl derivatives of lanthanides with fluoro olefins. Izv. Akad. Nauk. SSSR, Ser. Khim. 1988, 445-450.

22. Crouse, G.D.; Webster, J.D. Addition of fluorinated olefins to ester enolates. Synthesis of fluorinated carboxylic esters and tetrafluorocyclobutanes. J. Org. Chem. 1992, 57, 6643-6646.

23. Ohashi, M.; Kamura, R.; Doi, R.; Ogoshi, S. Preparation of Trifluorovinyl Compounds by Lithium Salt-promoted Monoalkylation of Tetrafluoroethene. Chem. Lett. 2013, 42, 933-935.

24. Beletskaya, I.P. The cross-coupling reactions of organic halides with organic derivatives of tin, mercury and copper catalyzed by palladium. J. Organomet. Chem. 1983, 250, 551-564.

25. Gillet, J.-P.; Sauvetre, R.; Normant, J.-F. Preparation et reactivite de fluorovinylzincs. Tetrahedron Lett. 1985, 26, 3999-4002.

26. Heinze, P.L.; Burton, D.J. Palladium catalyzed coupling of F-cinyl zinc reagents with aryl iodides. An improved synthesis of $\alpha, \beta, \beta$-trifluorostyrenes and the stereospecific preparation of 1-phenyl-F-propenes. J. Fluor. Chem. 1986, 31, 115-119. 
27. Tellier, F.; Sauvetre, R.; Normant, J.F.; Dromzee, Y.; Jeannin, Y. Réactivité des diènes et styrènes fluorés obtenus par réaction de couplage au palladium. J. Organomet. Chem. 1987, 331, 281-298 (In French).

28. Heinze, P.L.; Burton, D.J. Palladium-catalyzed cross-coupling of perfluoroalkenylzinc reagents with aryl iodides. A new, simple synthesis of $\alpha, \beta, \beta$-trifluorostyrenes and the stereoselective preparation of 1-arylperfluoropropenes. J. Org. Chem. 1988, 53, 2714-2720.

29. Anilkumar, R.; Burton, D.J. A remarkable room temperature preparation of the trifluorovinylzinc reagent from HFC-134a. A cost-effective, high yield synthesis of $\alpha, \beta, \beta$-trifluorostyrenes. Tetrahedron Lett. 2002, 43, 2731-2733.

30. Raghavanpillai, A.; Burton, D.J. Room Temperature Preparation of Trifluoroethenylzinc Reagent by Metalation of the Readily Available Halocarbon HFC-134a and an Efficient, Economically Viable Synthesis of 1,2,2-Trifluorostyrenes. J. Org. Chem. 2004, 69, 7083-7091.

31. Lechel, T.; Dash, J.; Hommes, P.; Lentz, D.; Reissig, H.-U. Three-Component Synthesis of Perfluoroalkyl- or Perfluoroaryl-Substituted 4-Hydroxypyridine Derivatives and Their Palladium-Catalyzed Coupling Reactions. J. Org. Chem. 2010, 75, 726-732.

32. Roemer, M.; Lentz, D. Autocatalytic formation of fluorinated ferrocenophanes from 1,1'-bis(trifluorovinyl)ferrocene. Chem. Commun. 2011, 47, 7239-7241.

33. Roemer, M.; Schmiel, P.; Lentz, D. Cymantrene- and Ferrocene-Based Complexes with Perfluorinated Bridging Moieties. Organometallics 2011, 30, 2063-2066.

34. Duric, S.; Schmidt, B.M.; Ninnemann, N.M.; Lentz, D.; Tzschucke, C.C. Synthesis of Trifluorostyrene Derivatives by Palladium-Catalyzed Cross-Coupling of Lithium Trimethoxy(trifluorovinyl)borate with Aryl Bromides. Chem. Eur. J. 2012, 18, 437-441.

35. Frohn, H.J.; Adonin, N.Y.; Bardin, V.V.; Starichenko, V.F. Highly efficient cross-coupling reactions with the perfluoroorganotrifluoroborate salts $\mathrm{K}\left[\mathrm{R}_{\mathrm{F}} \mathrm{BF}_{3}\right]\left(\mathrm{R}_{\mathrm{F}}=\mathrm{C}_{6} \mathrm{~F}_{5}, \mathrm{CF}_{2}=\mathrm{CF}\right)$. Tetrahedron Lett. 2002, 43, 8111-8114.

36. Yamamoto, T.; Yamakawa, T. Pd-Catalyzed Arylation of Chlorotrifluoroethylene Using Arylboronic Acids. Org. Lett. 2012, 14, 3454-3457.

37. Xu, C.; Chen, S.; Lu, L.; Shen, Q. Preparation of Trifluorostyrenes via Palladium-Catalyzed Coupling of Arylboronic Acids with Chloro- and Bromotrifluoroethylene. J. Org. Chem. 2012, 77, 10314-10320.

38. Park, J.D.; Benning, A.F.; Downing, F.B.; Laucius, J.F.; McHarness, R.C. Synthesis of Tetrafluorethylene-Pyrolisis of monochlorodifluoromethane. Ind. Eng. Chem. 1947, 39, 354-358.

39. Arcella, V.; Troglia, C.; Ghielmi, A. Hyflon Ion Membranes for Fuel Cells. Ind. Eng. Chem. Res. 2005, 44, 7646-7651.

40. Ameduri, B.; Boutevin, B. Copolymerization of fluorinated monomers: Recent developments and future trends. J. Fluor. Chem. 2000, 104, 53-62.

41. Ohashi, M.; Kambara, T.; Hatanaka, T.; Saijo, H.; Doi, R.; Ogoshi, S. Palladium-Catalyzed Coupling Reactions of Tetrafluoroethylene with Arylzinc Compounds. J. Am. Chem. Soc. 2011, 133, 3256-3259.

42. Richmond, T.G. Organometallic Transformations Demonstrate That Fluorocarbons Are Reactive Molecules. Angew. Chem. Int. Ed. 2000, 39, 3241-3244. 
43. Braun, T.; Perutz, R.N. Routes to fluorinated organic derivatives by nickel mediated C-F activation of heteroaromatics. Chem. Commun. 2002, doi:10.1039/B206154F.

44. Jones, W.D. Activation of $\mathrm{C}-\mathrm{F}$ bonds using $\mathrm{Cp}_{2}{ }_{2} \mathrm{ZrH}_{2}$ : A diversity of mechanisms. Dalton Trans. 2003, doi:10.1039/B307232K.

45. Torrens, H. Carbon-fluorine bond activation by platinum group metal complexes. Coord. Chem. Rev. 2005, 249, 1957-1985.

46. Meier, G.; Braun, T. Catalytic C-F Activation and Hydrodefluorination of Fluoroalkyl Groups. Angew. Chem. Int. Ed. 2009, 48, 1546-1548.

47. Amii, H.; Uneyama, K. C-F Bond Activation in Organic Synthesis. Chem. Rev. 2009, 109, 2119-2183.

48. Sun, A.D.; Love, J.A. Cross coupling reactions of polyfluoroarenes via C-F activation. Dalton Trans. 2010, 39, 10362-10374.

49. Braun, T.; Wehmeier, F. C-F Bond Activation of Highly Fluorinated Molecules at Rhodium: From Model Reactions to Catalysis. Eur. J. Inorg. Chem. 2011, doi:10.1002/ejic.201001184.

50. Clot, E.; Eisenstein, O.; Jasim, N.; Macgregor, S.A.; McGrady, J.E.; Perutz, R.N. C-F and C-H Bond Activation of Fluorobenzenes and Fluoropyridines at Transition Metal Centers: How Fluorine Tips the Scales. Acc. Chem. Res. 2011, 44, 333-348.

51. Klahn, M.; Rosenthal, U. An Update on Recent Stoichiometric and Catalytic C-F Bond Cleavage Reactions by Lanthanide and Group 4 Transition-Metal Complexes. Organometallics 2012, 31, 1235-1244.

52. Nova, A.; Mas-Ballesté, R.; Lledós, A. Breaking C-F Bonds via Nucleophilic Attack of Coordinated Ligands: Transformations from $\mathrm{C}-\mathrm{F}$ to $\mathrm{C}-X$ Bonds $(X=\mathrm{H}, \mathrm{N}, \mathrm{O}, \mathrm{S})$. Organometallics 2012, 31, 1245-1256.

53. Kuehnel, M.F.; Lentz, D.; Braun, T. Synthesis of Fluorinated Building Blocks by Transition-Metal-Mediated Hydrodefluorination Reactions. Angew. Chem. Int. Ed. 2013, 52, 3328-3348.

54. Kemmitt, R.D.W.; Moore, R.D. Tetrafluoroethylene complexes of platinum(0). J. Chem. Soc. A 1971, doi:10.1039/J19710002472.

55. Booth, B.L.; Casey, G.C.; Haszeldine, R.N. Reactions involving transition metals: XII. Some attemps to prepare alkulidynetrirhodium cluster compounds. J. Organomet. Chem. 1981, 219, 401-408.

56. Anderson, D.J.; McDonald, R.; Cowie, M. Carbon-Fluorine Bond Activation in Fluoroolefins: Clear Documentation of Cooperative C-F Bond Activation by Adjacent Metal Centers. Angew. Chem. Int. Ed. 2007, 46, 3741-3744.

57. Ohashi, M.; Shibata, M.; Saijo, H.; Kambara, T.; Ogoshi, S. Carbon-Fluorine Bond Activation of Tetrafluoroethylene on Palladium(0) and Nickel(0): Heat or Lewis Acidic Additive Promoted Oxidative Addition. Organometallics 2013, 32, 3631-3639.

58. Ohashi, M.; Saijo, H.; Shibata, M.; Ogoshi, S. Palladium-Catalyzed Base-Free Suzuki-Miyaura Coupling Reaction of Fluorinated Alkenes and Arenes via Palladium Fluoride Key Intermediate. Eur. J. Org. Chem. 2013, doi:10.1002/ejoc.201201405. 
59. Schaub, T.; Backes, M.; Radius, U. Catalytic C-C Bond Formation Accomplished by Selective C-F Activation of Perfluorinated Arenes. J. Am. Chem. Soc. 2006, 128, 15964-15965.

60. Schaub, T.; Radius, U. Efficient $\mathrm{C}-\mathrm{F}$ and $\mathrm{C}-\mathrm{C}$ Activation by a Novel $N$-Heterocyclic Carbene-Nickel(0) Complex. Chem. Eur. J. 2005, 11, 5024-5030.

61. Schaub, T.; Fischer, P.; Steffen, A.; Braun, T.; Radius, U.; Mix, A. C-F Activation of Fluorinated Arenes using NHC-Stabilized Nickel(0) Complexes: Selectivity and Mechanistic Investigations. J. Am. Chem. Soc. 2008, 130, 9304-9317.

62. Fischer, P.; Götz, K.; Eichhorn, A.; Radius, U. Decisive Steps of the Hydrodefluorination of Fluoroaromatics using [Ni(NHC) 2 ]. Organometallics 2012, 31, 1374-1383.

63. Guo, H.; Kong, F.; Kanno, K.-I.; He, J.; Nakajima, K.; Takahashi, T. Early Transition Metal-Catalyzed Cross-Coupling Reaction of Aryl Fluorides with a Phenethyl Grignard Reagent Accompanied by Rearrangement of the Phenethyl Group. Organometallics 2006, 25, 2045-2048.

64. Nakamura, Y.; Yoshikai, N.; Ilies, L.; Nakamura, E. Nickel-Catalyzed Monosubstitution of Polyfluoroarenes with Organozinc Reagents Using Alkoxydiphosphine Ligand. Org. Lett. 2012, 14, 3316-3319.

65. Ohashi, M.; Doi, R.; Ogoshi, S. Palladium-Catalyzed Coupling Reaction of Perfluoroarenes with Diarylzinc Compounds. Chem. Eur. J. 2014, 20, 2040-2048.

66. Recently, $\mathrm{Lu}$ and Shen reported the molecular structure of the related trifluorovinyl palladim(II) chloride, trans- $\left(\mathrm{PPh}_{3}\right)_{2} \mathrm{Pd}(\mathrm{Cl})\left(\mathrm{CF}=\mathrm{CF}_{2}\right)$, whereas the trifluorovinyl complex was prepared via oxidative addition of the $\mathrm{C}-\mathrm{F}$ bond of chlorotrifluoroethylene. See Ref. [37].

67. Bartlett, P.D.; Cohen, G.M. Dimers of $\alpha, \beta, \beta$-trifluorostyrene. J. Am. Chem. Soc. 1973, 95, 7923-7925.

68. Achonduh, G.T.; Hadei, N.; Valente, C.; Avola, S.; O’Brien, C.J.; Organ, M.G. On the role of additives in alkyl-alkyl Negishi cross-couplings. Chem. Commun. 2010, 46, 4109-4111.

69. Burton et al. claimed that some of ( $\alpha, \beta, \beta$-trifluoro)styrene derivatives are prone to cyclodimerize under a higher concentration (especially in pure form) condition even at room temperature or below. See also Ref. [28].

70. Miyaura, N.; Suzuki, A. Palladium-Catalyzed Cross-Coupling Reactions of Organoboron Compounds. Chem. Rev. 1995, 95, 2457-2483.

71. Suzuki, A.; Brown, H.C. Organic Syunthesis via Boranes; Aldrich: Milwaukee, WI, USA, 2003.

72. Hall, D.G. Boronic Acids; Wiley-VCH: Weinheim, Germany, 2005.

73. Miyaura, N. Metal-Catalyzed Reactions of Organoboronic Acids and Esters. Bull. Chem. Soc. Jpn. 2008, 81, 1535-1553.

74. Suzuki, A. Cross-Coupling Reactions Of Organoboranes: An Easy Way To Construct C-C Bonds (Nobel Lecture). Angew. Chem. Int. Ed. 2011, 50, 6722-6737.

75. Widdowson, D.A.; Wilhelm, R. Palladium catalysed cross-coupling of (fluoroarene)tricarbonylchromium(0) complexes. Chem. Commun. 1999, doi:10.1039/A906256D.

76. Widdowson, D.A.; Wilhelm, R. Palladium catalysed Suzuki reactions of fluoroarenes. Chem. Commun. 2003, doi:10.1039/B212138G.

77. Kim, Y.M.; Yu, S. Palladium(0)-Catalyzed Amination, Stille Coupling, and Suzuki Coupling of Electron-Deficient Aryl Fluorides. J. Am. Chem. Soc. 2003, 125, 1696-1697. 
78. Mikami, K.; Miyamoto, T.; Hatano, M. A highly efficient asymmetric Suzuki-Miyaura coupling reaction catalyzed by cationic chiral palladium(II) complexes. Chem. Commun. 2004, doi:10.1039/B407250B.

79. Steffen, A.; Sladek, M.; Braun, T.; Neumann, B.; Stammler, H.-G. Catalytic C-C Coupling Reactions at Nickel by $\mathrm{C}-\mathrm{F}$ Activation of a Pyrimidine in the Presence of a $\mathrm{C}-\mathrm{Cl}$ Bond: The Crucial Role of Highly Reactive Fluoro Complexes. Organometallics 2005, 24, 4057-4064.

80. Bahmanyar, S.; Borer, B.C.; Kim, Y.M.; Kurtz, D.M.; Yu, S. Proximity Effects in the Palladium-Catalyzed Substitution of Aryl Fluorides. Org. Lett. 2005, 7, 1011-1014.

81. Liu, J.; Robins, M.J. Fluoro, Alkylsulfanyl, and Alkylsulfonyl Leaving Groups in Suzuki Cross-Coupling Reactions of Purine 2'-Deoxynucleosides and Nucleosides. Org. Lett. 2005, 7 , 1149-1151.

82. Cargill, M.R.; Sandford, G.; Tadeusiak, A.J.; Yufit, D.S.; Howard, J.A.K.; Kilickiran, P.; Nelles, G. Palladium-Catalyzed C-F Activation of Polyfluoronitrobenzene Derivatives in Suzuki-Miyaura Coupling Reactions. J. Org. Chem. 2010, 75, 5860-5866.

83. Sun, A.D.; Love, J.A. Nickel-Catalyzed Selective Defluorination to Generate Partially Fluorinated Biaryls. Org. Lett. 2011, 13, 2750-2753.

84. Yu, D.; Shen, Q.; Lu, L. Selective Palladium-Catalyzed C-F Activation/Carbon-Carbon Bond Formation of Polyfluoroaryl Oxazolines. J. Org. Chem. 2012, 77, 1798-1804.

85. Breyer, D.; Braun, T.; Kläring, P. Synthesis and Reactivity of the Fluoro Complex trans- $\left[\mathrm{Pd}(\mathrm{F})\left(4-\mathrm{C}_{5} \mathrm{NF}_{4}\right)\left({ }^{i} \mathrm{Pr}_{2} \mathrm{PCH}_{2} \mathrm{CH}_{2} \mathrm{OCH}_{3}\right)_{2}\right]$ : C-F Bond Formation and Catalytic $\mathrm{C}-\mathrm{F}$ Bond Activation Reactions. Organometallics 2012, 31, 1417-1424.

86. Miyaura, N. Cross-coupling reaction of organoboron compounds via base-assisted transmetalation to palladium(II) complexes. J. Organomet. Chem. 2002, 653, 54-57.

87. Carrow, B.P.; Hartwig, J.F. Distinguishing Between Pathways for Transmetalation in Suzuki-Miyaura Reactions. J. Am. Chem. Soc. 2011, 133, 2116-2119.

88. Gooßen, L.J.; Ghosh, K. Palladium-Catalyzed Synthesis of Aryl Ketones from Boronic Acids and Carboxylic Acids or Anhydrides. Angew. Chem. Int. Ed. 2001, 40, 3458-3460.

89. Tsukamoto, H.; Sato, M.; Kondo, Y. Palladium(0)-catalyzed direct cross-coupling reaction of allyl alcohols with aryl- and vinyl-boronic acids. Chem. Commun. 2004, doi:10.1039/B402256D.

90. Tobisu, M.; Xu, T.; Shimasaki, T.; Chatani, N. Nickel-Catalyzed Suzuki-Miyaura Reaction of Aryl Fluorides. J. Am. Chem. Soc. 2011, 133, 19505-19511.

91. Morken, P.A.; Campbell, R.F.; Burton, D.J. Preparation of the E- and Z-heptafluorobutenyl-2zinc reagent by zinc-induced dehalogenation/metallation of 2,2-dibromo-octafluorobutane. J. Fluor. Chem. 1994, 66, 81-85.

92. Jasim, N.A.; Perutz, R.N.; Whitwood, A.C.; Braun, T.; Izundu, J.; Neumann, B.; Rothfeld, S.; Stammler, H.-G. Contrasting Reactivity of Fluoropyridines at Palladium and Platinum: $\mathrm{C}-\mathrm{F}$ Oxidative Addition at Palladium, $\mathrm{P}-\mathrm{C}$ and $\mathrm{C}-\mathrm{F}$ Activation at Platinum. Organometallics 2004, 23, 6140-6149.

93. Macgregor, S.A.; Roe, D.C.; Marshall, W.J.; Bloch, K.M.; Bakhmutov, V.I.; Grushin, V.V. The $\mathrm{F} / \mathrm{Ph}$ Rearrangement Reaction of $\left[\left(\mathrm{Ph}_{3} \mathrm{P}\right)_{3} \mathrm{RhF}\right]$, the Fluoride Congener of Wilkinson's Catalyst. J. Am. Chem. Soc. 2005, 127, 15304-15321. 
94. Braun, T.; Steffen, A.; Schorlemer, V.; Neumann, B.; Stammler, H.-G. Routes to unique palladium A-frame complexes with a bridging fluoro-ligand. Dalton Trans. 2005, doi:10.1039/B509032F.

95. GC-MS analysis of the crude product revealed this catalytic reaction gave a small percentage of a coupling product with a formula of $\mathrm{C}_{10} \mathrm{H}_{5} \mathrm{~F}_{7}(\mathrm{~m} / \mathrm{z}=256)$. This undesired coupling product might generate via 7.

96. Dmowski, W. An improved synthesis of 1-phenylpentafluoropropenes. J. Fluor. Chem. 1981, 18, 25-30.

97. Amatore, C.; Jutand, A.; le Duc, G. The Triple Role of Fluoride Ions in Palladium-Catalyzed Suzuki-Miyaura Reactions: Unprecedented Transmetalation from [ArPdFL 2 C Complexes. Angew. Chem. Int. Ed. 2012, 51, 1379-1382.

98. Mankad, N.P.; Toste, F.D. C-C Coupling Reactivity of an Alkylgold(III) Fluoride Complex with Arylboronic Acids. J. Am. Chem. Soc. 2010, 132, 12859-12861.

99. Krasovskiy, A.; Malakhov, V.; Gavryushin, A.; Knochel, P. Efficient Synthesis of Functionalized Organozinc Compounds by the Direct Insertion of Zinc into Organic Iodides and Bromides. Angew. Chem. Int. Ed. 2006, 45, 6040-6044.

100. Kashiwabara, T.; Tanaka, M. Decarbonylative Coupling of Fluorobenzoyl Chlorides with Hexamethyldisilane in the Presence of a Palladium Complex Catalyst: Extremely Facile Decarbonylation of Pentafluorobenzoyl-Pd Complex Relevant to $\mathrm{C}_{6} \mathrm{~F}_{5} \mathrm{SiMe}_{3}$ Formation. Organometallics 2006, 25, 4648-4652.

101. Tao, S.; Weng, Z.; Hor, T.S.A. 1,1'-P/O-Ferrocenyl Ligands in Palladium-Catalyzed Suzuki Coupling of Aryl Chlorides. Organometallics 2006, 25, 1199-1205.

102. Barrios-Landeros, F.; Carrow, B.P.; Hartwig, J.F. Effect of Ligand Steric Properties and Halide Identity on the Mechanism for Oxidative Addition of Haloarenes to Trialkylphosphine $\operatorname{Pd}(0)$ Complexes. J. Am. Chem. Soc. 2009, 131, 8141-8154.

103. Uson, R.; Fornies, J.; Gimeno, J.; Espinet, P.; Navarro, R. Bis(pentafluorophenyl)complexes of palladium(II) and of platinum(II). J. Organomet. Chem. 1974, 81, 115-122.

104. Uson, R.; Fornies, J.; Navarro, R. A new route for the synthesis of binuclear organometallic and inorganic palladium(II) complexes. Inorg. Chim. Acta 1979, 33, 69-75.

(C) 2014 by the authors; licensee MDPI, Basel, Switzerland. This article is an open access article distributed under the terms and conditions of the Creative Commons Attribution license (http://creativecommons.org/licenses/by/3.0/). 